\title{
ARTICLE \\ The use of noncash payment methods for regular payments and the household demand for cash: evidence from Japan
}

\author{
Hiroshi Fujiki ${ }^{1}$
}

Received: 19 June 2018 / Revised: 7 January 2020 / Accepted: 17 January 2020 / Published online: 31 July 2020 (c) The Author(s) 2020, corrected publication 2020

\begin{abstract}
Understanding the demand for cash and noncash payment methods is an important policy concern in Japan, as the Japanese government aims at a cashless economy. Previous studies show that the demand for specific payment methods depends not only on the motivations of the kind of transactions, such as day-to-day transactions or hoarding, but also on payment contexts, such as bill payments or online payments. However, a few studies have investigated the demand for payment methods by payment context in Japan. We fill this gap by examining Japanese family and single-person household data on the choice of cash and noncash payment methods for regular payments, including bill payments. We found a decreasing popularity of choices involving automatic withdrawals and an increasing popularity of choices involving credit cards in both data sets and that of choosing exclusively cash in the single-person households' data. We also found that these changes are associated with a decreasing demand for cash in family households and, conversely, an increasing demand in single-person households, assuming that the current pace of gradual adoption of noncash payment methods continues. In promoting a cashless society, the Japanese government should pay attention to the finding that a more frequent use of credit cards for regular payments is not always associated with a decrease in the demand for cash.
\end{abstract}

JEL Classification D14 · E41

Hiroshi Fujiki

fujiki@tamacc.chuo-u.ac.jp

1 Faculty of Commerce, Chuo University, 742-1 Higashinakano, Hachioji-shi, Tokyo 192-0393, Japan 


\section{Introduction}

\subsection{Background, motivation, and major results}

In this paper, we examine the use of noncash payment methods with a special attention to regular payments in Japan. To convey to readers the importance of this research, this subsection begins by explaining the area of payment economics and why empirical economists care about the choice of payment method, especially cash and noncash payments. The subsection then explains the policy issues arising concerning the choice of payment methods unique to Japan, and argues why regular payments are a worthwhile direction of inquiry. The subsection ends by briefly summarizing the most important empirical findings in the paper.

First, payment economics studies the mechanics of exchange, especially payment systems. The glossary of payments and market infrastructure terminology by the Committee on Payments and Market Infrastructures (CPMI) (2016) classifies payment systems into large-value payment systems (LVPS) and retail payment systems, with LVPS being a funds transfer system that typically handles large-value high-priority payments. Typically, LVPS settles obligations between banks, and, therefore, includes the BOJ-NET in Japan and the Fedwire in the US. In contrast, a retail payment system is a funds transfer system that typically handles a large volume of relatively low-value payments in forms such as checks, credit transfers, direct debits, and card payment transactions, and, thus, includes Zengin-Net in Japan and the Automated Clearing House (ACH) in the US.

In studying payment systems, payment economics views the choice of payment methods and the structure of the institutional arrangements that support them as endogenous, as argued in Lacker (2005). In particular, payment economics examines the kinds of financial frictions that lead to a particular payment method and its relationships with financial intermediation and technological advances (see Kahn and Roberds (2009) for details). Reflecting this motivation, as Lacker (2005) has summarized, payments economics lies at the intersection of monetary and banking economics with industrial organization. Theoretical studies on payment economics include search theoretic models and industrial organization models, including models that focus on the US credit card industry. See Nosal and Rocheteau (2011) and Rysman and Wright (2014) and their respective reviews.

For the most part, empirical work on retail payment systems economics began by examining the consumer choice of electronic payment methods to understand better the possible reasons behind the puzzling slow adoption of electronic payment methods over cash and checks. Because the US Federal Reserve has been responsible for both check clearing and cash circulation, Federal Reserve economists needed to know the timing of the shift toward newer electronic payments to reduce the resources for check clearing and cash circulation in a timely manner. According to Li et al. (2019), US payment experts have predicted the arrival of the cashless and checkless society for several decades. However, despite the supply of electronic payment services by US financial institutions, including the 
introduction of credit cards in the 1950s, the ACH in the 1970s and debit cards in the 1980s, the adoption of electronic payment methods has been painfully slow.

Since the mid-1990s, the Federal Reserve has begun studying the consumer demand for payment instruments more explicitly, because they believed that the reason for this delayed adoption lay on the consumer side. For instance, an early empirical analysis by Stavins (2002) using the US Survey of Consumer Finances' data found that younger and more educated consumers with higher incomes were more likely to use electronic payments such as ATM, debit, credit and smart cards, direct deposits, and direct payments. Other empirical studies in several other economies have used point-of-sale data and central bank methods of payment surveys to respond to the policy question on the choice between cash and noncash payment methods after considering any cross-country differences in payment technology and infrastructure. See Stavins (2017) for a review, including cross-country comparisons, and Rysman and Schuh (2017) for a discussion of the role of mobile payments, faster payments, and virtual currencies.

Second, Japan shares much the same history as the US of a relatively slow adoption of electronic payment methods, such as credit cards and electronic money, by consumers. However, Japan is somewhat unique in that its consumers successfully adopted bank account transfers or automatic withdrawal (an arrangement where a depositor will grant permission to companies to take payments from the depositor's bank account automatically and regularly, say once a month) as early as the 1970s (note that unlike the US, the Japanese do not use personal checks). Hence, it is worthwhile for an empirical payment economist to investigate the slow adoption of electronic payment methods (the flipside of the coin is the persistent usage of cash) using Japanese data to facilitate cross-country comparison, not least with the US.

Note that in making cross-country comparisons on the recent increase in the cash usage (usually the ratio of the amount of cash in circulation to nominal GDP) in many advanced economies (including Japan), economists reach strikingly different conclusions about whether they explicitly analyze the motivations for cash demand, either for day-to-day payments or for store of value (cash hoarding). They thus reach quite different policy recommendations depending on which motivations behind the cash demand they focus on, as the following three lines of inquiry demonstrate.

First, Haasl et al. (2018) have argued that "[i]n Japan, a largely cash-based economy where the use of credit cards and other electronic payments is relatively uncommon, currency demand now stands at nearly $19 \%$ of GDP - the highest of any countries for which the Bank for International Settlements collects statistics" (1). They undertook simulations of US cash demand based on three different scenarios for the four key determinants of cash demand: (1) the size of the economy, (2) the adoption of new payment technologies that replace currency, (3) changes in interest rates, and (4) changes in foreign demand. However, they provided no evidence that the usage of credit cards and other electronic payments was relatively uncommon based on Japanese micro survey data, and did not measure Japanese cash usage depending on the four factors.

Second, Fujiki and Nakashima (2019) interpret the strong Japanese cash demand by drawing on two different motivations for holding and using cash. They argue that the demand for hoarding in Japan was so strong that it outweighed the negative 
effect of the substitution toward noncash means of payment for day-to-day payments as follows. To start, Fujiki and Tanaka (2018a) and Fujiki and Nakashima (2019) showed that the determinants of the choice of day-to-day payment methods in Japan were not very different from those shown in the US, the Eurozone, and Canada, because the Japanese used both cash and electronic money for small-value day-today transactions, and credit cards for large-value day-to-day transactions. Therefore, in terms of the second factor for cash demand suggested by Haasl et al. (2018), their assertion of Japan as a largely cash-based economy is misleading at least for day-today transactions.

In addition, Fujiki and Nakashima (2019) demonstrate that the strong cash demand in Japan must be the result of hoarding during the long period of low interest rates given a stable log-log cash demand function from 1995 to 2015 , such that $42 \%$ of the total cash in circulation in 2017 could result from cash hoarding. These results are consistent with the theoretical predictions based on the third factor for cash demand suggested by Haasl et al. (2018). Finally, regarding the fourth factor for cash demand suggested by Haasl et al. (2018), to our knowledge, there is no estimate of the foreign demand for Japanese banknotes.

Third, Khiaonarong and Humphrey (2019) argue that Japan might not actually be a cash-based economy as often asserted. They measure cash usage in 11 countries $^{1}$ using three additional ratios to the conventional ratio of the amount of cash in circulation to nominal GDP. These are: (1) household consumption minus cash payment substitutes (the residual of household consumption paid by debit, credit card, and electronic money) divided by household consumption, (2) the share of cash withdrawals from ATMs and over the counter in household consumption, and (3) the share of cash withdrawals from ATMs and over the counter in total cash and cash-like payments (card and electronic money transactions). Based on their second measure, Japanese cash usage $(82 \%)$ is the second highest in the world following Germany (84\%).

However, based on their third measure, Japanese cash usage $(6 \%)$ is the lowest among 11 economies along with Norway (7\%). Based on their fourth measure, Japanese cash usage (23\%) is lower than US cash usage (29\%), the fourth-lowest cash usage among the 11 economies. Judging from the consistency of ranking across four measures, Khiaonarong and Humphrey (2019) argue that their preferred measure is (3), and thus maintain that Japan is not a cash-based economy. However, the second and third measures are likely to reflect transaction demand each year and the marginal increase in the demand for hoarding, rather than the stock of cash hoarding. Thus, we should take their results as evidence that Japan is not a cash-based economy with day-to-day payments.

Whether we explicitly analyze the motivations for cash demand, either for dayto-day payments or as a store of value (cash hoarding) matters, because these three lines of inquiry offer different possible policy recommendations for the Japanese government and its aim of a cashless economy. The Ministry of Economy, Trade and

\footnotetext{
1 Khiaonarong and Humphrey (2019) use data from Australia, China, Denmark, Germany, India, Japan, The Netherlands, Norway, Singapore, the UK, and the US.
} 
Industry of Japan (METI) will subsidize cashless payments in some registered retail shops for nine months following the increase in the consumption tax rate on October 12019 , and plans to increase the cashless payment ratio from 20 to $40 \%$ by 2025 . Hence, it is a real-time policy issue. Unfortunately, we cannot obtain useful policy implications for the temporary subsidy of cashless payments from the results in Haasl et al. (2018), because they did not consider why Japanese consumers choose cash over noncash payment methods for day-to-day payments.

Alternatively, if we were to rely upon the findings in Fujiki and Nakashima (2019), the temporary subsidy of cashless payments could replace relatively smallvalue day-to-day cash payments for noncash payments. Hence, its effect on total cash demand (including hoarding) would be small. Importantly, if the Japanese government truly wants to move to a cashless economy by reducing cash hoarding, an increase in the interest rate would be a promising policy recommendation. For example, the estimates in Fujiki and Nakashima (2019) suggest that if Japan were to escape from its liquidity trap (owing to the success of Abenomics and the planned increase in Japanese GDP to 600 trillion yen by 2020) and were the Bank of Japan to raise interest rates by up to $2 \%$, the cash-GDP ratio would be about $8 \%$. This suggests that cash demand in Japan would halve. In contrast, where we to draw upon the preferred measure of cash usage in Khiaonarong and Humphrey (2019), the temporary subsidization of cashless payments would be unnecessary, because Japan is not a cash-based economy, at least as far as day-to-day transactions are concerned. We believe that the more balanced policy implication arises from Fujiki and Nakashima's (2019) analysis of the demand for cash for both day-to-day payments and as a store of value.

Finally, if we were to accept that the choice of payment methods is worth investigating in Japan, why would we specifically care about regular payments? Hereafter, we take regular payments as regularly scheduled payments such as utility bill payments (say, utility bills for gas, electricity, water, and telephone) following the definition of the Survey of Household Finances (SHF) conducted by the Central Council for Financial Services Information, as used in our subsequent analysis. Unfortunately, there are no consistent statistics for regular payments. However, the following data suggest that it could be between 10 and $20 \%$ of total household expenditure (or households' withdrawals from bank accounts). First, according to the 2017 Family Income and Expenditure Survey, utility bills for gas, electricity, water, and telephones account for about $12 \%$ of total monthly spending by the typical Japanese family household.

Second, according to Mochizuki (2019), between January and June 2018, depositors paid their monthly wage bill in their banking accounts held in one of the three largest Japanese private banks withdrew their deposits in the following way: $45 \%$ by cash using ATMs and 55\% by bank transfers and automatic withdrawals. Note that regular payments are likely through either credit card payments deducted from the cardholders' bank accounts or automatic withdrawals from the bank account. Those represent $16 \%$ and $2 \%$ of the value of withdrawals, respectively, or about $20 \%$ of the value of withdrawals together.

For an international comparison of Japanese regular payments, we refer to US bill payments (a payment made to a company or person at some date after the company 
or person has provided goods or services to a consumer, likely to occur at regular frequencies ${ }^{2}$ ). According to the 2018 Survey of Consumer Payment Choice (SCPC) summarized in Foster et al. (2019, Table 7), bill payments represent about $30 \%$ of the number of US consumer payments overall. Among these bill payments, $30 \%$ are by automatic bill payment, ${ }^{3} 30 \%$ are by online bill payment ${ }^{4}$, and $40 \%$ are by mail, in person or by phone (Foster et al. 2019, Table 10).

Having stated the definition and quantitative importance of regular payments, we offer two reasons for our focus on regular payments. First, the choice of payment methods depends on the payment context, say, making payments between persons or making bill payments. As an example, according to the Survey of the Japanese Bankers Association (JBA 2019, p. 92), the Japanese use cash heavily for day-to-day person-to-person transactions and automatic withdrawals for utility bill payments (usually at regular frequencies). More precisely, $73 \%$ of cash users, $23 \%$ of bank transfer users, and $11 \%$ of automatic withdrawal users use these payment methods for day-to-day person-to-person transactions. In contrast, $16 \%$ of cash users, $35 \%$ of bank transfer users, and $65 \%$ of automatic withdrawals users use them for utility bill payments.

As a US example, according to the 2018 SCPC, 98\%, 78\%, 97\%, and $80 \%$ of consumers (see Table 2 in Foster et al. (2019)) adopt cash, check, card (debit, credit, and prepaid), and electronic (online banking bill and bank account number payments either automatically or online) payments, respectively. The use of cash, check, card, and electronic payments account for 30\%, 3\%, 64\%, and $2 \%$ of the number of purchase (including online and retail purchases of goods and services ${ }^{5}$ ) and personto-person payment ${ }^{6}$ (see Table 11 in Foster et al. (2019)). In contrast, the use of cash, check, card, and electronic payments accounts for $10 \%, 7 \%, 50 \%$, and $29 \%$ of the number of bill payments [see Table 10 in Foster et al. (2019)].

In sum, Japanese consumers tend to choose automatic withdrawals more often for bill payments and usually at regular frequencies compared with day-to-day personto-person payments. Similarly, while most US consumers have adopted card, cash, and electronic payments, they often use cash and card payments for purchases and person-to-person payments, and card and electronic payments for bills. The choice of payment methods then depends on the appropriate context, for example, payments

\footnotetext{
${ }^{2}$ Examples of bill payments include a payment to a utility company for energy services provided during a month or a payment to service a loan such as a mortgage.

3 Automatic bill payment is a bill payment set up to occur on a regularly scheduled basis, typically monthly. Once established, these do not require any additional effort on the consumer's part and can be processed via bank account deductions, through debit card transactions or credit card charges or paid directly from the consumer's income.

4 Online bill payment is a payment made from a bank's website or mobile app that accesses funds from a customer's checking or savings account to pay a bill or other people. This payment does not require the bank or its customers to disclose the bank account number to a third party.

${ }^{5}$ Examples of retail purchases are goods in stores and the purchase of retail services such as those made at restaurants, bars, fast food and beverage establishments, transportation and toll locations, or doctor's visits, or for childcare, haircuts, education, recreation, or entertainment.

6 A person-to-person payment is a payment to people not made through a retail establishment, such as payments for allowances, repaying a friend, or presenting gifts.
} 
for between persons or bill payments, as pointed out in Koulayev et al. (2016). Therefore, it makes sense to analyze the choice of payment methods in Japan with respect to the context of payment, not only for day-to-day payments as in Fujiki and Tanaka (2018a) but also for regular payments.

Second, the choice of regular payment methods in Japan relates to the choice of payment methods for bill payments in the US, and, therefore, is deserving of a crosscountry comparison. In the US, using the 2008 SCPC, Koulayev et al. (2016) found that bank account number payments were the most popular method for automatic and online bill payments. They examined the effect of the increase in the cost of using debit cards due to changes in regulation on the use of other payment methods given two payment contexts: bill payments and retail payments. ${ }^{7}$ They found that not credit cards, but rather checks and bank account number payments were close substitutes for debit cards with bill payments. They also found that cash and credit cards were substitutes for debit cards for retail payments.

Rysman and Schuh (2017) cited these results and suggested the study of payment methods specific to bill payments as an important area for future work, because Koulayev et al. (2016) showed that bill payments explain the popularity of bank account number payments as an alternative to a debit card. The evidence also suggests that new payment innovations with implications for bill payment may be particularly attractive. However, at the time, Rysman and Schuh (2017) were aware of very few studies focusing on bill payments, or other data sets that would even allow for a detailed study of bill payment behavior.

In Japan, the SHF shows that automatic withdrawals are the favorite choice of regular payment method. Regular payments are one of the earliest examples of Japanese consumers adopting electronic payments, mainly through the choice of automatic withdrawals as long ago as the 1970s, and even preceding the widespread use of credit cards and electronic money. However, some may also have begun paying their utility bills by credit card, arguably because many major credit cards offer discounts for their points reward program. If we were to identify a shift from automatic withdrawals to credit cards, it would be possibly unique to Japan. This is because the frequency of the use of cash, card and electronic payments in the US accounts for a mostly stable $10 \%, 50 \%$, and 25\% of bill payments from 2015 to 2019 (see Foster et al. (2019), Table 10).

Conversely, if we were to identify a shift from automatic withdrawals to cash, it would be inconsistent with the common understanding of a gradual shift from cash to electronic payments including automatic withdrawals observed in many economies including Japan. The Japanese government should appreciate the reasons behind such a shift, if any, because it is at once at odds with their policy objective

\footnotetext{
7 The 2008 SCPC defines retail payments as the sum of essential retail payments (a payment made in person to buy basic goods from retail outlets including: grocery stores, supermarkets, food stores, restaurants, bars, coffee shops, superstores, warehouses, club stores, drug or convenience stores and gas stations), and nonessential retail payment (a payment made in person to buy other goods from retailers, including: general merchandise, department stores, electronics and appliances stores, home goods, hardware stores, furniture stores, office supply stores and other miscellaneous and specialty stores). See Foster et al. (2009) for details.
} 
of a cashless society. To infer the reasons behind the changes in the choice of regular payment methods, if any, we should examine what demographic variables, such as age, income, gender, or educational attainment, relate to the less frequent use of automatic withdrawals and the more frequent use of credit cards or cash. However, despite strong academic interest, the lack of individual data on regular payments has acted against research in this area. We address this using unique survey data on the choice of payment methods for regular payments from 2007 to 2014 in Japan.

The major empirical findings in this paper are as follows. We first show that automatic withdrawals play an important role in regular payments in Japan, as bank account number payments do in US bill payments. We identify a gradual shift from automatic withdrawals to credit cards for regular payments in the family household data, which is unique within the electronic payment methods observed in Japan. We also find that the use of credit cards is associated with younger household heads, and this is consistent with the previous findings in both Japan and abroad. However, in the single-person household data, the popularity of both credit cards and cash surprisingly increased. Regrettably, we do not know to what extent this finding is attributable to our Japanese data set. However, the evidence supporting the increasing choice of cash is a unique and challenging finding.

\subsection{Background to Japanese regular payments}

It is well known that the Japanese use cash widely for day-to-day transactions. Less well known is the fact that the Japanese have also used automatic withdrawals (direct debits or Kouza Furikae in Japanese) widely for regular payments since the early 1970s, including the payment of gas, electricity, water, and telephone utility bills, rather than using cash, personal checks, or credit cards. ${ }^{8}$ In most cases, it is not depositors, but the companies that pay the fees for this service to the banks.

Automatic withdrawal is one of the primary services included in the financial service packages provided by major Japanese banks since 1972 (so-called Sogo Kouza in Japanese). The others are direct payroll deposits, cash cards for online cash dispensers, and automated teller machines (ATMs), and overdrafts from savings deposits. Because Sogo Kouza are free of charge, the problem of the "unbanked" has not been a major policy issue in Japan. Prior to Sogo Kouza, workers would receive their monthly wage in cash, pay any utility bills or provide for day-to-day spending using cash, and then deposit any remaining cash into the bank branch holding their account. Following the introduction of Sogo Kouza, workers now withdraw the necessary cash using an ATM card from any bank branch and allow the automatic withdrawal service to pay for any utility bills. Where the deposited amount is less than the bill payment, an overdraft from the savings deposit (usually up to $90 \%$ of the outstanding amount) enables settlement. Given the time saving from the use of the automatic withdrawal service, it has been the default payment method for regularly scheduled payments until recently.

$\overline{8}$ The following discussion draws on Nemoto (2008). Fujiki (2019) provides additional details. 
The Japanese tend to pay for their regular payments using not only automatic withdrawals, but also credit cards and cash. The use of credit cards became popular in Japan especially after the 1990s, reflecting the increase in overseas travel and Internet transactions by the Japanese. Regarding the increasing choice of credit cards, the points reward programs offered by some credit card companies for making regular payments with them seem to be the main reason. As evidence, an annual survey conducted by the Japan Credit Bureau (one of the oldest credit card issuers in Japan) shows that the key reason for most Japanese paying by credit card was the ease of accumulating points in credit card points' reward programs. ${ }^{9}$ To support this hypothesis, in subsection 2.2, we show that if a household chooses credit cards for regular payments, it also tends to choose credit cards to pay for high-value day-today transactions when compared with households choosing to pay using automatic withdrawals for regular payments. Note that the use of installment or revolving payments (standard payment methods for US credit cards) is likely not the main advantage for Japanese households choosing credit cards, because about $90 \%$ of credit card holders choose to pay using only one-time payments. ${ }^{10}$

Regarding the use of cash for regular payments, the deregulation of the Japanese financial industry, which allows national convenience store chains to accept utility bill payments by cash on behalf of the utility companies, seems to be a primary reason. Behind this deregulation lies the fact that Japanese banks were once very reluctant to accept utility bill payments, because the utility companies and the tax office refused to pay sufficient service charges, and thus banks required their depositors to use instead the automatic withdrawal service. ${ }^{11}$ The acceptance of bill payments by cash on behalf of utility companies in convenience stores began with the acceptance of electronic utility bill payments in the Kanto region in 1987, followed by the acceptance of bill payments for some local taxes and national health insurance premiums in 2003. Payment acceptance service companies, which introduced a unified bar code for bills, are behind these bill payments in convenience stores.

This was useful for depositors who prefer not to use credit cards to pay their utility bills, and who would then withdraw cash from ATMs in the convenience store and then submit their utility bills and cash to the cashier in the same store. However, unlike the teller counters in banks and post offices, service in the convenience stores was quick and available on a 24/7/365 basis. Consequently, bill payment by cash seems to be a reasonable choice for households frequently visiting convenience stores.

\footnotetext{
9 The survey is available from https://www.global.jcb/ja/press/news_file/file/report2018.pdf (Accessed March 15, 2019).

10 See the evidence on p. 22 of the 2017 edition of the Japanese consumer credit statistics from the Japan Consumer Credit Association.

11 Note that a depositor can also pay utility bills using bank transfers (Kouza Furikomi in Japanese). In this case, a depositor will pay utility bills using either cash at an ATM, at a bank counter, or using Internet banking. However, for bank transfers, the depositor, not the utility company, incurs the cost of transferring money in many cases.
} 
Proportion of observations for payment method for all payments (choose up to two of five options)

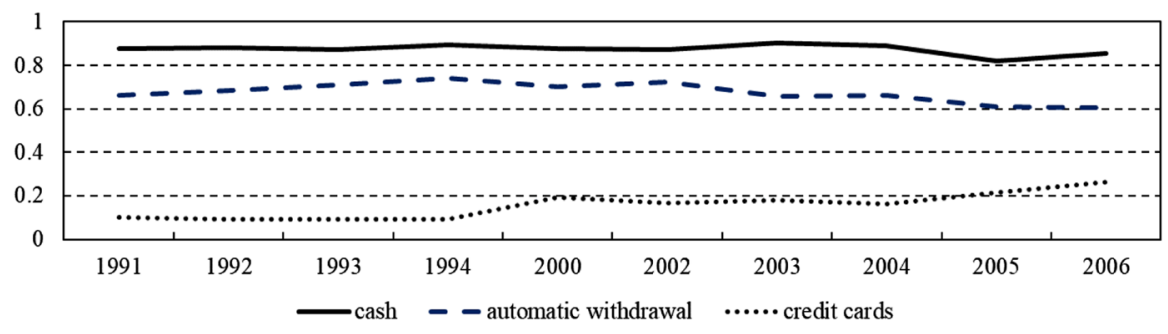

Fig. 1 Choice of payment method in Japan. Source: SHF 1991-1994, 2000, 2002-2006

\subsection{Preview of the data}

Many Japanese, especially the middle-aged and elderly, have taken Sogo Kouza for granted for some time. Figure 1 illustrates the proportion of the two most-favored methods of payment (including for day-to-day and regular payments) from five options: cash, credit cards, debit cards, automatic withdrawal, and other, from 1991 to 1994 , in 2000, and from 2002 to 2006, as reported in the SHF. Figure 1 clearly illustrates the heavy reliance of Japanese consumers on cash and automatic withdrawal, with survey respondents choosing cash (the solid line) and automatic withdrawal (the dashed line) accounting for anywhere between $80-90 \%$ and $60-70 \%$ of all respondents, respectively. ${ }^{12}$

However, note that Fig. 1 also shows that respondents choosing credit cards (the dotted line) increased to $25 \%$ in 2006 , suggesting that these circumstances are changing rapidly. Since 2007, the SHF has provided information on the two favorite methods of payment for two types of transactions: day-to-day transactions and regular payments. Regarding the two most-favored methods for regular payments, it asks respondents to select from the five options of "cash (hereafter Cash)," "credit cards (hereafter Card)," "electronic money (including debit cards)," "automatic withdrawal (hereafter $A W$ )," and "other" for samples of family and single-person households. About $98 \%$ of the respondents select one of the following six choices, comprising Cash only, Card and Cash (hereafter Card \& Cash), Cash and AW (hereafter Cash \& $A W$ ), Card only, Card \& $A W$ (hereafter Card \& $A W$ ), and $A W$ only. In this paper, we focus on these six choices from 2007 to 2014.

The upper panel in Table 1 provides the percentages for the six choices made by the sample family households from 2007 to 2014 and the percentage point changes in the proportions from 2007 to 2014 (the row labeled "Changes from 2007 to 2014"). The table also details the total number of observations from 2007 to 2014, the percentage of this for each of the six choices, and the average cash holdings,

\footnotetext{
12 Because survey respondents may select up to two options, it is possible that the sum of the proportions of households choosing cash and bank transfers exceeds one. In addition, the SHF has changed its sampling methods and survey questions a number of times, so the series reported in Fig. 1 is not consistently measured.
} 
Table 1 Choice of regular payment method

\begin{tabular}{|c|c|c|c|c|c|c|}
\hline \multicolumn{7}{|l|}{ Family household data } \\
\hline Year & Cash only & Card \& Cash & Cash \& $A W$ & Card only & Card \& $A W$ & AW only \\
\hline 2007 & $8.2 \%$ & $1.8 \%$ & $24.2 \%$ & $2.7 \%$ & $10.2 \%$ & $52.9 \%$ \\
\hline 2008 & $8.0 \%$ & $2.0 \%$ & $24.2 \%$ & $3.2 \%$ & $9.8 \%$ & $52.8 \%$ \\
\hline 2009 & $7.4 \%$ & $2.6 \%$ & $24.3 \%$ & $3.6 \%$ & $12.4 \%$ & $49.7 \%$ \\
\hline 2010 & $7.5 \%$ & $3.2 \%$ & $23.0 \%$ & $4.8 \%$ & $13.4 \%$ & $48.1 \%$ \\
\hline 2011 & $7.3 \%$ & $3.3 \%$ & $22.7 \%$ & $5.4 \%$ & $15.7 \%$ & $45.5 \%$ \\
\hline 2012 & $6.8 \%$ & $3.2 \%$ & $23.5 \%$ & $6.0 \%$ & $14.3 \%$ & $46.1 \%$ \\
\hline 2013 & $7.0 \%$ & $3.4 \%$ & $20.6 \%$ & $7.1 \%$ & $16.2 \%$ & $45.6 \%$ \\
\hline 2014 & $7.3 \%$ & $4.2 \%$ & $19.9 \%$ & $7.5 \%$ & $15.6 \%$ & $45.6 \%$ \\
\hline Changes from 2007 to 2014 & $-0.9 \%$ & $2.4 \%$ & $-4.3 \%$ & $4.7 \%$ & $5.4 \%$ & $-7.3 \%$ \\
\hline Number of observations & 2154 & 872 & 6614 & 1477 & 3,919 & 13,995 \\
\hline $\begin{array}{l}\% \text { Total number of observa- } \\
\text { tions }\end{array}$ & $7.4 \%$ & $3.0 \%$ & $22.8 \%$ & $5.1 \%$ & $13.5 \%$ & $48.2 \%$ \\
\hline Average cash holdings & 13.35 & 15.75 & 14.06 & 12.09 & 11.57 & 14.76 \\
\hline $\begin{array}{l}\text { Standard error of cash } \\
\text { holdings }\end{array}$ & 50.46 & 51.55 & 41.88 & 34.53 & 27.40 & 44.05 \\
\hline Median cash holdings & 3.00 & 5.00 & 5.00 & 5.00 & 5.00 & 5.00 \\
\hline \multicolumn{7}{|l|}{$\begin{array}{l}\text { Single-person household } \\
\text { data }\end{array}$} \\
\hline Year & Cash only & Card \& Cash & Cash \& AW & Card only & Card \& $A W$ & AW only \\
\hline 2007 & $9.8 \%$ & $7.5 \%$ & $12.7 \%$ & $12.2 \%$ & $26.5 \%$ & $31.3 \%$ \\
\hline 2008 & $10.4 \%$ & $7.9 \%$ & $12.7 \%$ & $14.4 \%$ & $24.2 \%$ & $30.3 \%$ \\
\hline 2009 & $10.4 \%$ & $8.0 \%$ & $12.5 \%$ & $17.1 \%$ & $24.5 \%$ & $27.6 \%$ \\
\hline 2010 & $9.7 \%$ & $9.1 \%$ & $11.3 \%$ & $17.4 \%$ & $26.9 \%$ & $25.7 \%$ \\
\hline 2011 & $9.8 \%$ & $9.1 \%$ & $10.7 \%$ & $19.5 \%$ & $24.0 \%$ & $27.0 \%$ \\
\hline 2012 & $10.7 \%$ & $9.5 \%$ & $10.5 \%$ & $19.8 \%$ & $25.8 \%$ & $23.8 \%$ \\
\hline 2013 & $12.5 \%$ & $10.3 \%$ & $9.3 \%$ & $21.9 \%$ & $22.8 \%$ & $23.2 \%$ \\
\hline 2014 & $15.2 \%$ & $8.7 \%$ & $9.2 \%$ & $22.4 \%$ & $24.1 \%$ & $20.4 \%$ \\
\hline Changes from 2007 to 2014 & $5.4 \%$ & $1.3 \%$ & $-3.6 \%$ & $10.2 \%$ & $-2.4 \%$ & $-10.9 \%$ \\
\hline Number of observations & 2125 & 1685 & 2137 & 3480 & 4784 & 5038 \\
\hline $\begin{array}{l}\% \text { Total number of observa- } \\
\text { tions }\end{array}$ & $11.0 \%$ & $8.8 \%$ & $11.1 \%$ & $18.1 \%$ & $24.9 \%$ & $26.2 \%$ \\
\hline Average cash holdings & 15.79 & 20.28 & 12.78 & 18.32 & 16.97 & 17.45 \\
\hline $\begin{array}{l}\text { Standard error of cash } \\
\text { holdings }\end{array}$ & 62.21 & 66.76 & 49.06 & 60.80 & 60.26 & 61.20 \\
\hline Median cash holdings & 2.00 & 3.00 & 2.00 & 3.00 & 3.00 & 3.00 \\
\hline
\end{tabular}

Statistics on cash holdings are in units of 10,000 yen

standard errors, and medians for each choice. As shown, the favorite choices for family households are $A W$ only (48.2\% of all observations), Cash \& $A W(22.8 \%)$, and $\operatorname{Card} \& A W(13.5 \%)$, all of which include $A W$. However, we can also discern the declining choice of $A W$ only and Cash \& $A W$ over time. Specifically, the proportion 
of households choosing $A W$ only and Cash \& $A W$ decreased by 7.3 (from 52.9 to $45.6 \%$ ) and 4.3 (from 24.2 to $19.9 \%$ ) percentage points, respectively. The number of households choosing Cash only (7.4\% of all observations) was slightly decreased by 0.9 percentage points (from 8.2 to $7.3 \%$ ).

In their place, we can see an increase in the number of households making choices involving Card. Specifically, Card \& AW (13.5\% of all observations), Card only (5.1\%), and Card \& Cash (3.0\%) increased by 5.4 (from 10.2 to $15.6 \%$ ), 4.7 (from 2.7 to $7.5 \%$, and 2.4 (from 1.8 to $4.2 \%$ ) percentage points, respectively. Does this trend suggest the decreasing demand for cash as consumers use credit cards to make regular payments? Considering the bottom row, the average cash holdings of those choosing Card only (120.9 thousand yen) and Card \& AW (115.7 thousand yen) are lower than for those choosing AW only (147.6 thousand yen) and Cash \& $A W$ (140.6 thousand yen). While the average cash holdings of households choosing Card \& Cash (157.5 thousand yen) exceeds that for $A W$ only and Cash \& $A W$, it remains a less popular choice.

Accordingly, we anticipate that these changes should be associated with the decreasing demand for cash by family households, assuming that our inferences based on the unconditional average cash holdings are correct and noting that the standard errors of cash holding are large and the median cash holdings are relatively small compared with the average cash holdings. For their part, Fujiki and Tanaka (2018a) showed that holding key demographic factors constant, credit card users tend to have smaller cash holdings than cash users for day-to-day transaction values of more than 1000 yen using the same family household data from the SHF from 2007 to 2014 as in this study. ${ }^{13}$ Given the increasing choice of credit cards in dayto-day transactions, we could predict that the frequent choice of Card in regular payments in place of $A W$ is associated with the decreasing demand for cash.

The lower panel of Table 1 details the results for single-person households in a similar manner and again demonstrates the declining popularity of choices involving $A W$. Specifically, the percentage of households choosing $A W$ only (26.2\% of all observations), Card \& $A W(24.9 \%)$, and Cash \& $A W(11.1 \%)$ decreased by 10.9 percentage points (from 31.3 to $20.4 \%$ ), 2.4 percentage points (from 26.5 to $24.1 \%$ ), and 3.6 percentage points (from 12.7 to $9.2 \%$ ), respectively. The table also suggests the increasing popularity of choices involving Cash \& Card, with the percentage of households choosing Card only (18.1\% of all observations) and Card \& Cash (8.8\%) increasing by 10.2 percentage points (from 12.2 to $22.4 \%$ ), and 1.3 percentage points (from 7.5 to $8.7 \%$ ). However, unlike the family household data, the percentages of a household choosing Cash only (11.0\% of all observations) increased by 5.4 percentage points (from 9.8 to $15.2 \%$ ). The bottom row in the table shows that the average cash holdings of households with the two increasingly popular choices, Card only (183.2 thousand yen) and Card \& Cash (202.8 thousand yen), are larger than those of three decreasingly popular choices, comprising $A W$ only (174.5 thousand yen), Cash \& $A W$ (127.8 thousand yen), and Card \& $A W$ (169.7 thousand yen). Therefore, we would not argue that the declining popularity of choices involving $A W$ and the increasing popularity

${ }^{13}$ As of March 15, 2019, 1 US dollar=112 Japanese yen, so 1000 yen is equal to about 9 US dollars. 
of choices involving Card would necessarily lead to the decreasing demand for cash by single-person households. For their part, Fujiki and Tanaka (2018a) did not examine the single-person household dataset, and thus would have been unable to note the increasing popularity of Cash only.

\subsection{Research questions, strategies, and main results}

Based on the preliminary findings in Table 1, we pose two questions. First, what household characteristics are associated with choices involving Card and $A W$ in family and single-person households, and Cash only in single-person households? Second, is the decreasing choice of $A W$ and the increasing choice of Card in both family and single-person households and Cash in single-person households associated with the increasing or decreasing demand for cash by Japanese households?

To respond to the first question, we estimate a multinomial logit model to identify the key demographic variables distinguishing between households choosing Card, Cash, and $A W$. We find that households with younger household heads tend to have choices involving Card. We also find that households with more disposable income and financial assets tend to choose Card \& $A W$. In contrast, single-person households choosing Cash only tend to have fewer financial assets, lower financial literacy as measured by knowledge of the Deposit Insurance Corporation of Japan, less interest in the services provided by banks, are self-employed or part-time workers, and have lower levels of education.

For the second question, we compare the cash demands for households with increasingly popular choices (Card \& AW, Card only, and Card \& Cash in families and Card only, Cash only, and Card \& Cash for single persons) and decreasingly popular choices ( $A W$ only, Cash \& $A W$, and Cash only in families and $A W$ only, Cash \& $A W$, and Card \& $A W$ for single persons). We then compare the demand for cash using the simulated values from the estimates of a conditional demand for cash function and employing two matching techniques. We find that recent changes in the popularity of the choice of regular payments is associated with the decreasing (increasing) demand for cash in family (single-person) households.

\subsection{Literature}

This paper is an extension of the work by Fujiki and Tanaka (2018a). While we employ the same repeated cross-sectional data sets and statistical methods as in Fujiki and Tanaka (2018a), these authors did not consider the declining choice of $A W$ in regular payments and its effects on the cash usage, nor did they analyze the data for single-person households. For individual Japanese household data, Fujiki and Tanaka (2018b) focused on payment choices for day-to-day transaction values less than 1000 yen, but employed different statistical methods to Fujiki and Tanaka (2018a). Fujiki and Tanaka (2018a) provide a useful survey of other related Japanese literature. Our research also relates to work on the choice of consumer payment methods and their determinants, and the demand for cash in economies other than Japan. Recent studies in the area include Esselink and Hernández (2017) for the Eurozone, Greene et al. (2017), Koulayev et al. (2016), and Schuh and Briglevics 
(2014) for the US, Henry et al. (2018), Wakamori and Welte (2017) and Chen et al. (2017) for Canada, Jonker et al. (2018) for The Netherlands, and Lippi and Secchi (2009) for Italy. Bagnall et al. (2016) provides an international perspective using surveys of cross-country payment diaries.

The rest of the paper is organized as follows. Section 2 briefly explains the statistical model and discusses the data used for the analysis. Section 3 reports the estimation results for the choice of payment method and Sect. 4 details the results for the conditional cash demand function. Section 5 concludes after identifying some of the limitations of the analysis.

\section{Model and data}

In this section, we discuss the model and data used in the analysis. As the model is identical to that in Fujiki and Tanaka (2018a), we explain the main points only.

\subsection{Model}

Fujiki and Tanaka (2018a) specify a model of consumer demand for cash conditional on the choice of payment method. First, they assume that a multinomial logit model approximates a household's choice of payment method. In the context of this paper, assume that an indirect utility function $V_{i j t}$ of a household $i$ conditional on the choice of regular payment method $j=1$, Cash only, $j=2$, Card \& Cash, $j=3$, Cash and $A W, j=4$, Card only, $j=5$, Card \& $A W$, and $j=6, A W$ only, at time $t$ is approximated by the following linear function:

$$
V_{i j t}=X_{i j t} \delta_{j}+v_{i j t}, j=1, . ., 6,
$$

where $X_{i j t}$ is a vector of observable household characteristics, $\delta_{j}$ is a vector of parameters, and $v_{i j t}$ are unobservable preferences for payment method $j$ of household $i{ }^{14}$ If household $i$ at time $t$ chooses payment method $k$ instead of $l$, it means that $V_{i k t}>V_{i l t}, k \neq l$. Let $v_{i j t}$ follow an independent extreme value distribution whose cumulative distribution function is $\exp \left(-\exp \left(-v_{j}\right)\right)$ with respect to each payment choice $j=1, \ldots, 6$. Under these assumptions, Dubin and McFadden (1984) show that the choice of payment method follows a multinomial logit model, where the probability of the choice of payment method $j=1, \ldots, 5$ for household $i$ at time $t, P_{i j t}$ ,depends on $X_{i j t}$ in Eq. (1) after normalizing the parameter value for choice 6 to zero. We use the estimates of the multinomial logit model to identify the family characteristics related to the choice of method for the six types of payment.

Second, Fujiki and Tanaka (2018a) assume that conditional on the choice of payment method, the household determines the stock of cash holdings using a

\footnotetext{
14 See Fujiki (2019) for a model combining the choice of day-to-day and regular payment through aggregating the choice of day-to-day and regular payment methods.
} 
similar model to that in Dubin and McFadden (1984): one that corrects the selfselection bias from the choice of payment method approximated by the multinomial logit model. Fujiki and Tanaka (2018a) assume that the demand for cash conditional on the choice of payment method $j$ by household $i,\left(\bar{C}_{i j t} \mid \mathrm{j}\right.$ chosen $)$ is a linear function of both the household's observable characteristics $X_{i j t}$ and $\eta_{i j t}$. Fujiki and Tanaka (2018a) also assume that $\eta_{i j t}$ is a linear function of unobservable household $i$ 's preference for the payment methods and a random shock $u_{i j t}$, and thus $\eta_{i j t}=E \quad\left(\eta_{i j t} \mid v_{i 1 t}, v_{i 2 t}, v_{i 3 t}, v_{i 4 t}, v_{i 5 t}, v_{i 6 t}\right)+u_{i j t}$, where $E\left(u_{i j t}\right)=0$ and $\operatorname{Var}\left(u_{i j t}\right)=\sigma_{j}^{2}$. The conditional cash demand function then becomes:

$$
\begin{aligned}
E\left(\bar{C}_{i j t} \mathrm{l} \mathrm{j} \text { chosen }\right) & =X_{i j t} \beta_{j}+E\left(\eta_{i j t} \mathrm{lj} \text { chosen }\right) \\
& =X_{i j t} \beta_{j}+\left(\sigma_{j} \sqrt{6} / \pi\right) \sum_{k=1}^{6} R(j)_{k}\left(E\left(v_{i j t} \mathrm{lj} \text { chosen }\right)-\gamma\right),
\end{aligned}
$$

where $\gamma$ is Euler's constant, $R(j)_{k}$ are correlation coefficients of $\eta_{i j t}$ and $v_{i k t}$, $\sum_{k=1}^{6} R(j)_{k}=0$ and $\sum_{k=1}^{6} R(j)_{k}{ }^{2}<1$. We can estimate Eq. (2) by two steps, because Dubin and McFadden (1984) show that

$$
E\left(v_{i j t} \mid \mathrm{j} \text { chosen }\right)=\gamma-\log P_{i k t} \text { if } k=j,=\gamma+\left(P_{i k t} /\left(1-P_{i k t}\right)\right) \log P_{i k t} \text { if } k \neq j .
$$

We first run a multinomial logit model for the choice of payment method, and then use its estimate to simulate $P_{i k t}$ and plug this into Eqs. (3) and (2). We can estimate Eq. (2) by regressing the cash balances of households on $X_{i j t}$ and those terms that correct for sample selection as expressed by (3), along with the error terms using ordinary least squares.

We use the estimates of (2) to infer whether the current trend of increasing choices involving Card and decreasing choices involving $A W$ are associated with the increasing or decreasing demand for cash by Japanese households as follows. We first simulate the conditional cash demand function of households choosing payment method $j$ and those choosing $k$, and then compare the mean predicted conditional cash demand of the households choosing payment method $j$ and $k$ based on the usual t test.

We also estimate the average treatment effects (ATEs) and the average treatment effects of the treated (ATETs) of the choice of the jth payment method and not the $k$ th payment method to analyze the differences in the cash holdings of $j$ th and $k$ th payment method users as a robustness check, as in Fujiki and Tanaka (2018a). To achieve this, we first use the subgroup of observations choosing the $j$ th and $k$ th payment methods and estimate a logit model using the same demographic variables as Eq. (1) to compute the propensity score. We then move to propensity score matching and inverse probability weighting and compute the ATEs and ATETs. As these methods are independent of the specification of the conditional demand for cash, the ATEs and ATEs are a good robustness check for misspecification in the conditional cash demand in Eq. (2). 


\subsection{Data}

We employ individual household data from the SHF from 2007 to 2014. For each survey year, the SHF data comprises family and single-person household data sets. For the family household data, the SHF uses a stratified two-stage random sampling method to select 500 survey areas, and then randomly selects 16 households, consisting of two or more people from each area, totaling about 8000 samples. Of these, in each survey year, some 3300-4000 samples respond. The single-person household data set selected each survey year comprises 2500 respondents from a pool of individuals registered with a survey company through the Internet. The distribution of respondent ages (ranging from 20-69 years), genders, and regions is determined in such a way as to represent the population in the Japanese Census.

The SHF questions respondents about household financial assets and liabilities and financial products and their outstanding amounts (to the nearest 10,000 yen) and average cash holdings. The SHF also questions households about various household characteristics, including annual disposable income, area of residence, and the age, gender, education, and employment status of household members. Regarding the choice of regular payment methods, we focus on six choices, comprising Cash only, Card \& Cash, Cash \& AW, Card only, Card \& $A W$, and $A W$ only. We do this after first removing those respondents who did not provide a choice of payment method (129 respondents in the family household sample) or whose cash holdings exceeded 9 million yen (only five responses each from the 30,769 family and 20,000 single-person household samples). This process yields 29,031 family and 19,249 single-person observations.

Table 2 provides the means of the dummy variables identifying respondents who made mattress deposits (Mattress) to reduce investment risk. We assign a value of one to respondents increasing their cash holdings to reduce investment risk to themselves, either by reducing asset holdings or by suspending additional investment in other financial products. This variable controls for the large amount of cash holdings intended as savings, especially among the elderly, as explained by Otani and Suzuki (2008). The second row in Table 2 provides the mean of household size ( $\left.h \_s i z e\right)$ as measured by the number of household members, which is available for the family households only (the standard deviation is 1.30).

The next 20 rows detail the means of the dummy variables for the categories of annual disposable income (income) and the amount of financial assets (asset), being gross financial assets not net of financial liabilities. For example, income_0 takes a value of one for household respondents reporting zero annual disposable income, who are likely to be retirees, and zero otherwise. Income_0_200 takes a value of one for a family household that responds that its annual disposable income is greater than zero and lower than or equal to 2 million yen, and zero otherwise. Asset_0 then takes a value of one for households that respond with zero financial assets, and zero otherwise. ${ }^{15}$ We attempt to include ten even-sized categories, so that each contains a similar proportion of observations. However, because of the presence of mass points

\footnotetext{
15 Note that the responses for the stock of cash holdings are from a separate question. Thus, a respondent with zero financial assets could still have positive cash holdings.
} 
Table 2 Summary statistics (1)

Family household

\begin{tabular}{|c|c|c|c|}
\hline & Mean & & Mean \\
\hline Mattress & 0.014 & Mattress & 0.013 \\
\hline$h \_s i z e$ & 3.320 & & \\
\hline income_O & 0.006 & income_O & 0.063 \\
\hline income_200_260 & 0.104 & income_100_180 & 0.141 \\
\hline income_260_301 & 0.110 & income_180_250 & 0.173 \\
\hline income_301_370 & 0.071 & income_250_300 & 0.093 \\
\hline income_370_410 & 0.089 & income_300_350 & 0.134 \\
\hline income_410_500 & 0.061 & income_350_400 & 0.068 \\
\hline income_500_600 & 0.115 & income_400_500 & 0.106 \\
\hline income_600_700 & 0.081 & income_500_ & 0.128 \\
\hline income_700_900 & 0.101 & & \\
\hline income_900_ & 0.093 & & \\
\hline asset_o & 0.250 & asset_o & 0.339 \\
\hline asset_250_404 & 0.074 & asset_30_70 & 0.064 \\
\hline asset_404_600 & 0.064 & asset_70_120 & 0.064 \\
\hline asset_600_870 & 0.075 & asset_120_214 & 0.071 \\
\hline asset_870_1180 & 0.069 & asset_214_350 & 0.062 \\
\hline asset_1180_1620 & 0.070 & asset_350_550 & 0.070 \\
\hline asset_1620_2350 & 0.070 & asset_550_880 & 0.067 \\
\hline asset_2350_3800 & 0.069 & asset_880_1500 & 0.067 \\
\hline \multirow[t]{2}{*}{ asset_3800_ } & 0.070 & asset_1500_2800 & 0.066 \\
\hline & & asset_2800_ & 0.067 \\
\hline Know_Dep_Ins & 0.406 & Know_Dep_Ins & 0.438 \\
\hline Hear_Dep_Ins & 0.395 & Hear_Dep_Ins & 0.283 \\
\hline Lower_service_charge & 0.091 & Lower_service_charge & 0.183 \\
\hline Online_banking & 0.073 & Online_banking & 0.368 \\
\hline Debt & 0.414 & Debt & 0.264 \\
\hline Homeowner & 0.722 & Homeowner & 0.253 \\
\hline age $35-39$ & 0.078 & age $25-29$ & 0.193 \\
\hline age $40-44$ & 0.092 & age $30-34$ & 0.106 \\
\hline age $45-49$ & 0.093 & age $35-39$ & 0.107 \\
\hline age $50-54$ & 0.104 & age $40-44$ & 0.073 \\
\hline age $55-59$ & 0.117 & age $45-49$ & 0.051 \\
\hline age 60-64 & 0.129 & age 50-54 & 0.097 \\
\hline age $65-69$ & 0.111 & age 55-59 & 0.057 \\
\hline age $70-74$ & 0.090 & age 60-64 & 0.125 \\
\hline age 75- & 0.105 & age 65-69 & 0.055 \\
\hline Male & 0.923 & Male & 0.587 \\
\hline
\end{tabular}

Annual disposable income and the amount of financial assets are in units of 10,000 yen 
(relatively many observations at the same level of income or financial assets), we end up with between 8 and 10 categories.

The remaining rows report the means of the dummy variables of the proxies for financial knowledge, whether the individual is in debt, home ownership, age, and gender. We specify dummy variables for respondents who know about the Deposit Insurance Corporation of Japan and its role or who have heard about it (Know Dep_Ins and Hear_Dep_Ins, respectively). ${ }^{16}$ We then identify those who place an emphasis on lower service charges and online banking services offered via the Internet when selecting a financial institution (Lower_service_charge and Online_banking, respectively). These four variables should correlate with respondent financial knowledge. We also use dummy variables indicating whether a respondent has debt (Debt), is a homeowner (Homeowner), the age (in years) of the household head and whether the respondent's household has a male household head (Male). The dummy variables for the age of the household head (age) are 35-39, 40-44, 45-49, 50-54, $55-59,60-64,65-69,70-74$, and over 74 years for family households, so that all individual dummy variables include at least $7 \%$ of the data. For the single-person household data, the dummy variables for the ages of the household head are 25-29, $30-34,35-39,40-44,45-49,50-54,55-59,60-64$, and 65-69 years.

Table 3 reports the means of the dummy variables for educational levels, occupation, and the size of the city of residence (family households) and the region of residence (single-person households). We first specify dummy variables indicating the educational level of each survey respondent: senior high school (Senior_high), vocational college (Vocational_college), junior college (Junior_college), university (University), and graduate school (Graduate). There is an additional classification of junior high school and "other," but for the ease of empirical investigation, we add these together, because the number of households with "other" school is very small, and treat them as the base case in the following regressions. We also specify dummy variables indicating each respondent's job situation, including whether the household head is a full-time (Full_time) or part-time (Part_time) worker, selfemployed (Self_employed), or a student (Student). We also include a classification of no employment and does not attend school, which we specify as the base case in the following regressions.

For a family household, we also specify a dummy variable indicating spouse for the survey respondent's job situation and educational level, indicated by an $S_{-}$in front of the variable names for the job situation and educational level of the survey respondents. We also include a dummy variable for the family household that

\footnotetext{
16 The SHF does not include questions that allow us to construct a standard measure of financial literacy as surveyed by Lusardi and Mitchell (2014). Fujiki (2020) impute the missing financial literacy variable for the SHF in 2010 and 2016 by matching the standard measure of financial literacy in the 2010 wave of the Preference Parameters Study of Osaka University's 21st Century Center of Excellence Program and the Financial Literacy Survey 2016. Fujiki (2020) finds that that the imputed financial literacy variable yields high values for agents with a better knowledge of the Deposit Insurance Corporation of Japan, and thus suggests that responses to this question on the knowledge about the Deposit Insurance Corporation of Japan may, indeed, yield a useful proxy variable for the level of financial literacy where otherwise unavailable.
} 
Table 3 Summary statistics (2)

\begin{tabular}{|c|c|c|c|}
\hline \multicolumn{2}{|l|}{ Family household } & \multicolumn{2}{|l|}{ Single-person household } \\
\hline & Mean & & Mean \\
\hline Senior_high & 0.393 & Senior_high & 0.244 \\
\hline Vocational_college & 0.071 & Vocational_college & 0.099 \\
\hline Junior_college & 0.036 & Junior_college & 0.096 \\
\hline University & 0.253 & University & 0.443 \\
\hline Graduate & 0.024 & Graduate & 0.090 \\
\hline S_Senior_high & 0.396 & & \\
\hline S_Vocational_college & 0.085 & & \\
\hline S_Junior_college & 0.129 & & \\
\hline S_University & 0.097 & & \\
\hline S_Graduate & 0.004 & & \\
\hline Full_time & 0.518 & Full_time & 0.566 \\
\hline Part_time & 0.064 & Part_time & 0.098 \\
\hline Self_employed & 0.135 & Self_employed & 0.093 \\
\hline Student & 0.003 & Student & 0.086 \\
\hline S_Full_time & 0.144 & & \\
\hline S_Part_time & 0.239 & & \\
\hline S_Self_employed & 0.048 & & \\
\hline S_Student & 0.001 & & \\
\hline No_spouse & 0.109 & & \\
\hline Top20cities & 0.229 & Tohoku & 0.055 \\
\hline Cities_40k_ & 0.400 & Kanto & 0.396 \\
\hline Cities_20k_40k & 0.252 & Hokuriku & 0.029 \\
\hline Mattress_NA & 0.009 & Chubu & 0.121 \\
\hline income_NA & 0.102 & Kinki & 0.162 \\
\hline asset_NA & 0.055 & Chugoku & 0.050 \\
\hline$D e p \_I n s \_N A$ & 0.005 & Shikoku & 0.026 \\
\hline Banking_NA & 0.006 & Kyushu & 0.106 \\
\hline Debt_NA & 0.006 & & \\
\hline Homeowner_NA & 0.009 & & \\
\hline$a g e \_N A$ & 0.006 & & \\
\hline Male_NA & 0.002 & & \\
\hline$j o b \_N A$ & 0.058 & & \\
\hline$S \_j o b \_N A$ & 0.067 & & \\
\hline Education_NA & 0.100 & & \\
\hline S_Education_NA & 0.087 & & \\
\hline Number of observations & 29,031 & Number of observations & 19,249 \\
\hline
\end{tabular}

does not have a spouse of the household head (No_spouse). We include four size categories for cities based on their population in the family household data set. The city sizes are as follows: (1) the 20 largest cities, (2) cities with more than 40,000 households, (3) cities with between 20,000 and 40,000 households, and (4) cities with fewer than 20,000 households and villages. We use dummy variables to denote 
city size, being Top 20cities, Cities_40k_,Cities_20k_40k, and specify the category of cities with fewer than 20,000 households and villages as the base case in the following regressions. Regarding the single-person household data sets, we do not have data on the size categories for cities. Hence, we use the dummy variables for eight regions of residence (Tohoku, Kanto, Hokuriku, Chubu, Kinki, Chugoku, Shikoku, and Kyushu), and specify the dummy variables for Hokkaido as the base case in the following regressions.

We also specify dummy variables denoting the survey year (Year2007-Year2014). The remaining variables followed by _NA identify dummy variables for family households not reporting the variable before the _NA. For example, income_NA identifies households not reporting their annual disposable income. Banking_NA identifies households not responding to questions on either Lower_service_charges or Online_banking. This is because family household respondents can refuse to answer questions as they are in paper form, whereas in the Internet survey, the single-person household questionnaire requires respondents to respond to all questions before proceeding.

Do the choices of $A W$, Card, or Cash relate to some demographic variables? To respond, Table 4 details the average cash holdings (column labeled "Cash"), Disposable income, The amount of financial assets, age of the household heads (Age), dummy variables for respondents who know the Deposit Insurance Corporation of Japan and its role and who have heard about it (Know_Dep_Ins and Heard_Dep_ Ins), dummy variables for those who place an emphasis on lower service charges and online banking services offered via the Internet when selecting a financial institution (Lower_service_charge and Online_banking, respectively), and dummy variables for those who are self-employed and without a job (Self_employed and No_job, respectively) by the choice of six regular payment methods.

Table 4 also reports aggregate dummy variables for the choice of payment methods for day-to-day transactions: cash only_d (for respondents choosing cash exclusively), card_d (for respondents choosing credit card exclusively, cash and credit card, or credit card and other), compiled for day-to-day transaction values of less than or equal to 1000 yen (hereafter less than $1 \mathrm{k}$ ), more than 1000 yen and less than or equal to 5000 yen (hereafter 1-5 k), more than 5,000 yen and less than or equal to 10,000 yen (hereafter $5-10 \mathrm{k}$ ), more than 10,000 yen and less than or equal to 50,000 yen (hereafter $10-50 \mathrm{k}$ ), and more than 50,000 yen (hereafter $+50 \mathrm{k}$ ) as in Fujiki and Tanaka (2018a). The upper panel shows the average figures and the lower panel shows the deviation from the overall average. Figure 2 displays the average proportion of the six payment methods according to the dummy variables for age, disposable income and financial assets.

Table 4 suggests that households having choices involving Card tend to have more disposable income, younger household heads, place an emphasis on lower service charges and online banking services in selecting financial institutions, and have a lower proportion of households without a job. The top panel of Fig. 2 illustrates that the ratio of households choosing Card \& Cash (the thin dashed line), Card only (the thick solid line), and Card \& $A W$ (the thick dashed line) decreases with age. The middle panel of Fig. 2 also confirms that the proportions of households that choose Card only (the thick solid line) and Card \& $A W$ (the thick dashed line) increase with 
Table 4 Demographic variables by choice of payment method: family households

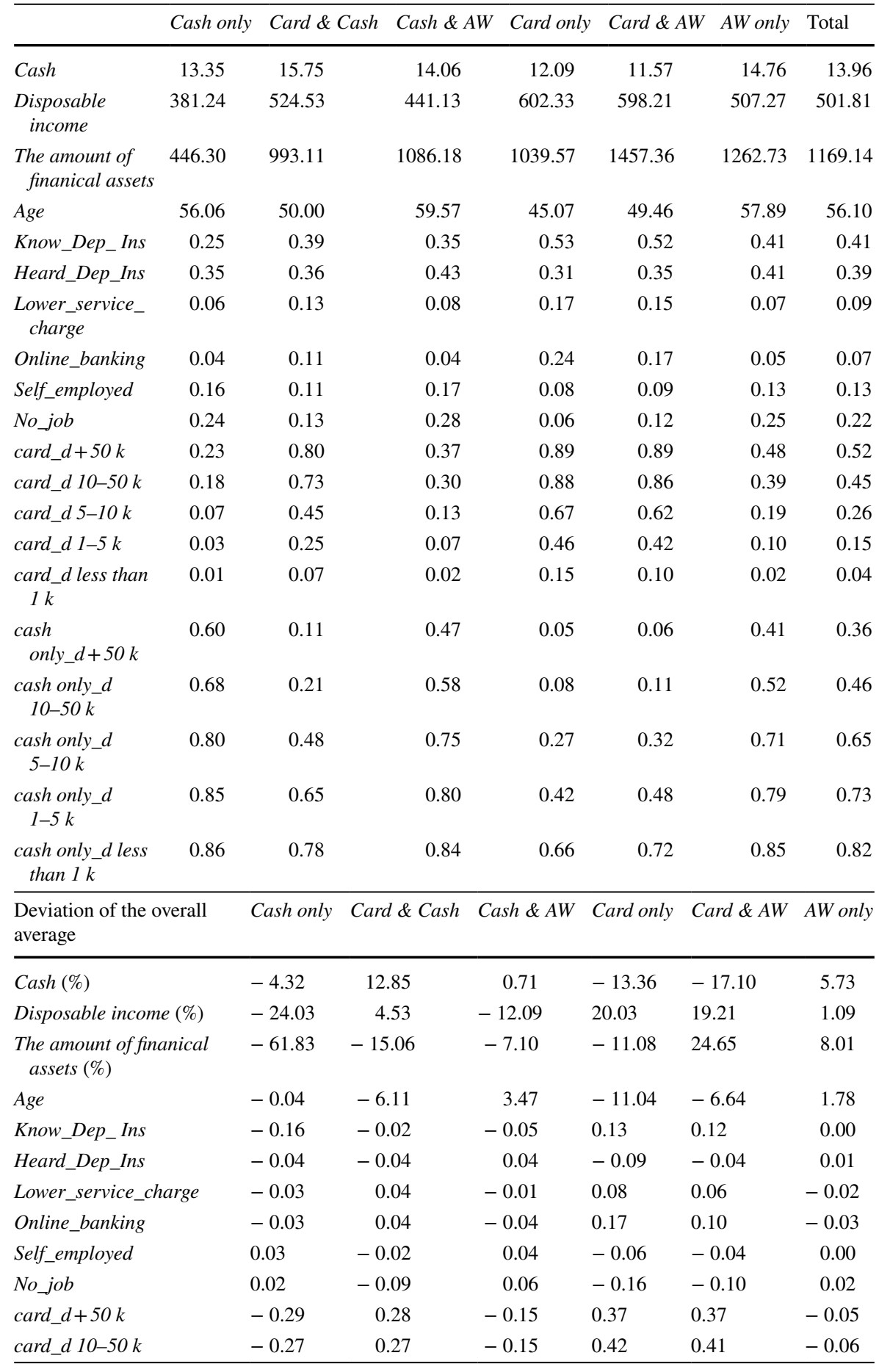


Table 4 (continued)

\begin{tabular}{llccccr}
$\begin{array}{l}\text { Deviation of the overall } \\
\text { average }\end{array}$ & Cash only & Card \& Cash & Cash \& AW & Card only & Card \& AW & AW only \\
\hline card_d 5-10 $k$ & -0.185 & 0.190 & -0.126 & 0.411 & 0.366 & -0.069 \\
card_d 1-5 $k$ & -0.126 & 0.100 & -0.079 & 0.308 & 0.264 & -0.056 \\
card_d less than 1 $k$ & -0.033 & 0.035 & -0.017 & 0.106 & 0.064 & -0.018 \\
cash only_d+50 $k$ & 0.234 & -0.253 & 0.104 & -0.309 & -0.300 & 0.047 \\
cash only_d 10-50 $k$ & 0.224 & -0.252 & 0.125 & -0.374 & -0.351 & 0.060 \\
cash only_d 5-10 $k$ & 0.156 & -0.169 & 0.103 & -0.377 & -0.324 & 0.068 \\
cash only_d 1-5 $k$ & 0.121 & -0.087 & 0.068 & -0.312 & -0.257 & 0.060 \\
cash only_d less than 1 $k$ & 0.043 & -0.044 & 0.019 & -0.163 & -0.105 & 0.034 \\
\hline
\end{tabular}

disposable income. Fujiki and Tanaka (2018a) identify these same features as key determinants of the choice of $c a r d \_d$. Indeed, the upper panel of Table 4 shows that these households very likely choose $c a r d \_d$ for making day-to-day payments more than 10,000 yen, especially Card \& $A W$ and Card only.

What is new in this table is that households choosing $A W$ only and Cash \& $A W$ tend to have older household heads without a job. The family households choosing Cash only tend to have less disposable income and fewer financial assets. The second and third panels in Fig. 2 also confirm that the ratio of households choosing Cash only decreases with disposable income and financial assets. Unsurprisingly, these households also tend to choose cash only_d, even for relatively high-value day-to-day transactions. However, Fujiki and Tanaka (2018a) did not identify the heterogeneity of Cash only (younger household heads) versus Cash \& $A W$ and $A W$ only (older household heads with possibly no job). Moreover, the average cash holdings of Cash only are smaller than for Card \& Cash and Cash \& AW, which seems to suggest that the choices of $A W$ and Card are not associated with smaller cash holdings. That is why, we need more thorough regression analysis.

Table 5 and Fig. 3 report the same information as Table 4 and Fig. 2 but for single-person households. Note that the single-person data set covers households to 69 years of age. The households choosing Cash only, whose proportion is gradually increasing, tend to have lower incomes, fewer financial assets, and younger household heads. The thin solid lines for the households who choose Cash only in Fig. 3 also confirm this point. The households choosing Cash only tend to choose cash $o n l y \_d$, even for relatively high-value day-to-day transactions.

Regarding the other choices, households choosing Card only tend to have more disposable income, more financial assets, and relatively younger household heads. This is similar to the family households. The thick solid lines in Fig. 3 for Card only are consistent with these observations. The households choosing AW only and Cash $\& A W$ tend to have lower incomes and are likely to have no job, and this is again consistent with the family households. The thick dotted lines for $A W$ only and thin dotted lines for Cash \& $A W$ in the second panel of Fig. 3 support these observations. Finally, households choosing Card \& Cash, Card only, and Card \& AW very likely choose card_ $d$ for making day-to-day payments more than 10,000 yen. Bearing this 

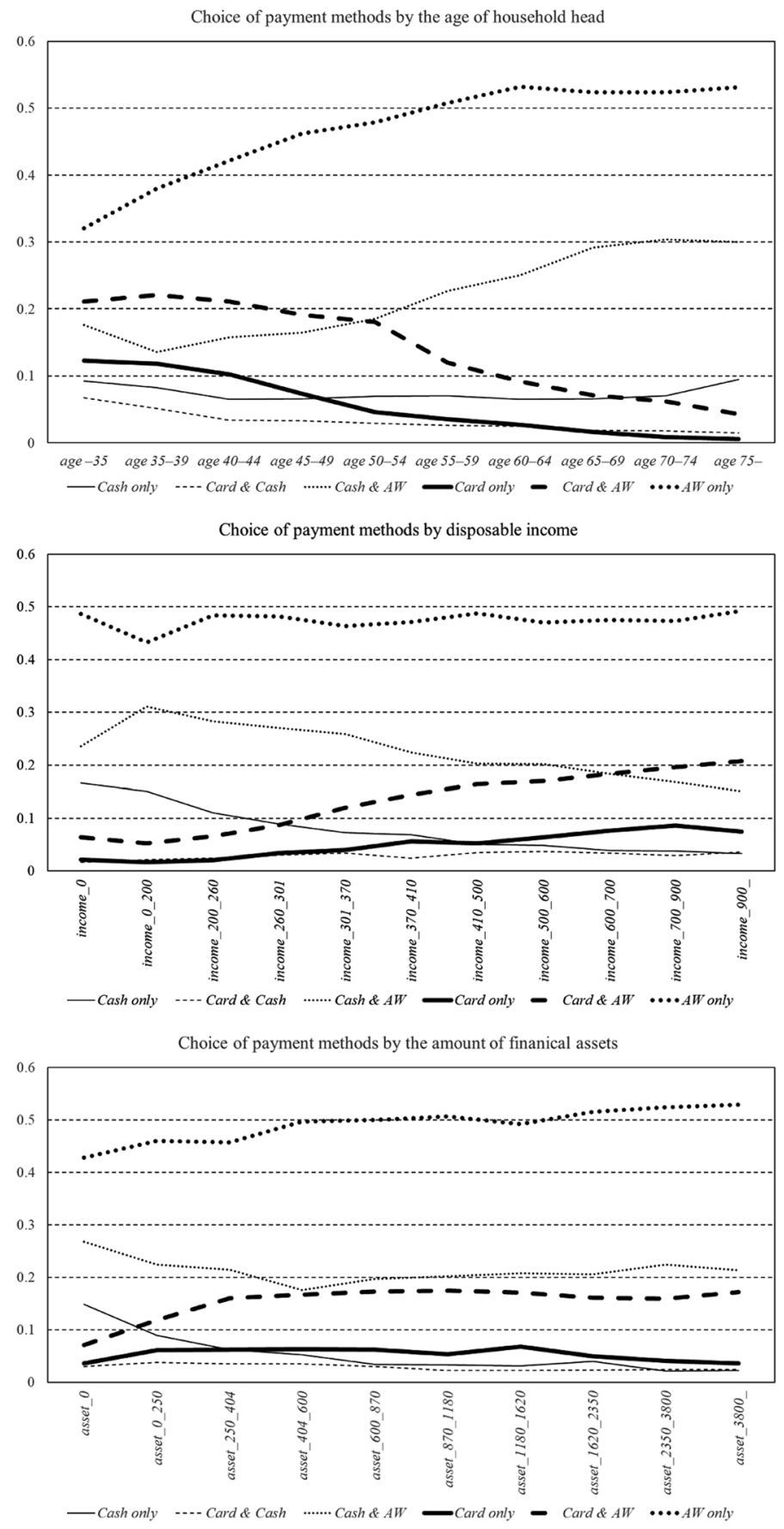

Fig. 2 Choice of payment method by the age of household head, disposable income, and financial asset holdings: family households 
Table 5 Demographic variables by choice of payment method: single-person households

\begin{tabular}{|c|c|c|c|c|c|c|c|c|c|}
\hline & Cash only & \multicolumn{2}{|c|}{ Card \& Cash } & \multicolumn{2}{|c|}{ Cash \& $A W$} & Card only & $y \quad C$ ard \& $A W$ & \multirow{2}{*}{$\frac{A W \text { only }}{17.45}$} & \multirow{2}{*}{$\frac{\text { Total }}{17.03}$} \\
\hline Cash & 15.79 & 20.28 & & 12.78 & & 18.32 & 16.97 & & \\
\hline $\begin{array}{l}\text { Disposable } \\
\text { income }\end{array}$ & 235.06 & 283.35 & & 245.32 & & 344.40 & 313.56 & 251.35 & 283.97 \\
\hline $\begin{array}{l}\text { The amount of } \\
\text { finanical assets }\end{array}$ & 221.71 & 488.94 & & 380.45 & & 839.86 & 1115.84 & 764.03 & 738.64 \\
\hline Age & 37.56 & 35.65 & & 40.85 & & 39.18 & 41.52 & 43.75 & 40.66 \\
\hline Know_Dep_Ins & 0.24 & 0.40 & & 0.36 & & 0.47 & 0.56 & 0.43 & 0.44 \\
\hline Heard_Dep_Ins & 0.26 & 0.26 & & 0.31 & & 0.26 & 0.26 & 0.32 & 0.28 \\
\hline $\begin{array}{l}\text { Lower_service_ } \\
\text { charge }\end{array}$ & 0.10 & 0.17 & & 0.18 & & 0.20 & 0.24 & 0.16 & 0.18 \\
\hline Online_banking & 0.24 & 0.37 & & 0.34 & & 0.42 & 0.46 & 0.31 & 0.37 \\
\hline Self_employed & 0.10 & 0.07 & & 0.13 & & 0.06 & 0.09 & 0.10 & 0.09 \\
\hline No_job & 0.14 & 0.10 & & 0.17 & & 0.12 & 0.16 & 0.21 & 0.16 \\
\hline$c a r d \_d+50 k$ & 0.29 & 0.86 & & 0.39 & & 0.93 & 0.92 & 0.59 & 0.70 \\
\hline card_d 10-50 k & 0.26 & 0.87 & & 0.38 & & 0.92 & 0.92 & 0.56 & 0.69 \\
\hline card_d 5-10 k & 0.19 & 0.71 & & 0.28 & & 0.82 & 0.79 & 0.39 & 0.56 \\
\hline card_d 1-5k & 0.12 & 0.53 & & 0.19 & & 0.63 & 0.60 & 0.25 & 0.41 \\
\hline $\begin{array}{l}\text { card_d less than } \\
\quad 1 \mathrm{k}\end{array}$ & 0.05 & 0.23 & & 0.07 & & 0.28 & 0.22 & 0.07 & 0.16 \\
\hline cashonly_d $+50 \mathrm{k}$ & 0.62 & 0.10 & & 0.50 & & 0.05 & 0.06 & 0.34 & 0.24 \\
\hline $\begin{array}{c}\text { cash only_d } \\
10-50 k\end{array}$ & 0.66 & 0.11 & & 0.54 & & 0.06 & 0.07 & 0.38 & 0.27 \\
\hline $\begin{array}{l}\text { cash only_d } \\
5-10 \mathrm{k}\end{array}$ & 0.74 & 0.25 & & 0.64 & & 0.14 & 0.17 & 0.54 & 0.38 \\
\hline cash only_d 1-5 $k$ & 0.76 & 0.36 & & 0.65 & & 0.25 & 0.27 & 0.62 & 0.46 \\
\hline $\begin{array}{l}\text { cashonly_dless } \\
\text { than } 1 k\end{array}$ & 0.78 & 0.52 & & 0.68 & & 0.41 & 0.45 & 0.71 & 0.58 \\
\hline $\begin{array}{l}\text { Deviation the overall } \\
\text { average }\end{array}$ & & Cash only & Card & $\&$ Cash & Casl & $h \& A W$ & Card only & Card \& $A W$ & AW only \\
\hline $\operatorname{Cash}(\%)$ & & -7.28 & 19.0 & & -24 & 4.97 & 7.56 & -0.39 & 2.43 \\
\hline Disposable income & $(\%)$ & -17.22 & -0.2 & & -13 & 3.61 & 21.28 & 10.42 & -11.49 \\
\hline $\begin{array}{l}\text { The amount of finani } \\
\text { assets }(\%)\end{array}$ & nical & -69.98 & -33.8 & & -48 & & 13.70 & 51.07 & 3.44 \\
\hline Age & & -3.10 & -5.0 & & 0.20 & & -1.48 & 0.86 & 3.10 \\
\hline Know_Dep_Ins & & -0.19 & -0.0 & & -0 . & & 0.04 & 0.12 & -0.01 \\
\hline Heard_Dep_Ins & & -0.02 & -0.0 & & 0.03 & & -0.02 & -0.02 & 0.04 \\
\hline Lower_service_char & Irge & -0.08 & -0.0 & & -0 & & 0.01 & 0.06 & -0.02 \\
\hline Online_banking & & -0.13 & 0.0 & & -0 . & & 0.05 & 0.10 & -0.06 \\
\hline Self_employed & & 0.01 & -0.0 & & 0.04 & & -0.03 & 0.00 & 0.01 \\
\hline No_job & & -0.01 & -0.0 & & 0.01 & & -0.04 & 0.00 & 0.05 \\
\hline card_d $+50 \mathrm{k}$ & & -0.41 & 0.1 & & -0 & & 0.23 & 0.22 & -0.11 \\
\hline card_d 10-50 k & & -0.42 & 0.1 & & -0 & & 0.23 & 0.23 & -0.13 \\
\hline card_d 5-10k & & -0.37 & 0.1 & & -0 & & 0.26 & 0.23 & -0.17 \\
\hline card_d 1-5k & & -0.29 & 0.1 & & -0 & & 0.23 & 0.19 & -0.16 \\
\hline
\end{tabular}


Table 5 (continued)

\begin{tabular}{llllllr}
\hline $\begin{array}{l}\text { Deviation the overall } \\
\text { average }\end{array}$ & Cash only & Card \& Cash & Cash \& AW & Card only & Card \& AW & AW only \\
\hline card_d less than 1 $k$ & -0.11 & 0.07 & -0.09 & 0.13 & 0.06 & -0.08 \\
cash only_d+50 $k$ & 0.38 & -0.15 & 0.26 & -0.20 & -0.19 & 0.09 \\
cash only_d 10-50 $k$ & 0.39 & -0.16 & 0.27 & -0.21 & -0.20 & 0.11 \\
cash only_d 5-10 $k$ & 0.35 & -0.13 & 0.26 & -0.24 & -0.21 & 0.16 \\
cash only_d 1-5 $k$ & 0.30 & -0.10 & 0.19 & -0.21 & -0.19 & 0.16 \\
cash only_d less than 1 $k$ & 0.20 & -0.06 & 0.10 & -0.17 & -0.13 & 0.13 \\
\hline
\end{tabular}

in mind, we move to the regression analysis to identify the demographic factors that determine the choice of payment methods and the conditional cash demand function.

\section{Choice of payment method}

Tables 6 and 7 provide the estimates of the marginal effects from the multinomial logit estimation of Eq. (4) using the pooled data from 2007 to 2014: ${ }^{17}$

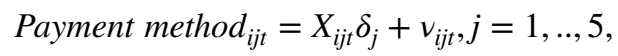

where Payment method is an indicator variable for the choice of payment method for regular payments $j$ made by individual $i$ at time $t, X_{i j t}$ is a vector of demographic variables, $\delta_{j}$ is a vector of parameters to be estimated, and $v_{i j t}$ are unobservable preferences for payment method $j$ of a household $i$, taking $A W$ only users as the base. All estimations use the STATA 14 command mlogit and margins. To conserve space, we do not report the parameter estimates for the survey years, dummy variables involving NAs, and heteroscedasticity consistent SEs. The asterisks *, **, and *** denote that the estimates are statistically significant at the $10 \%, 5 \%$, and $1 \%$ level, respectively.

In terms of the statistically significant parameter estimates, Table 6 provides the following interesting results. First, households with more disposable income tend to have a greater probability of choosing Card only \& Card and $A W$, while those with less disposable income have a greater probability of choosing Cash \& $A W$ and Cash only. This is consistent with the partial relationship in the middle panel of Fig. 2. Second, households with more financial assets have a greater probability of choosing Card \& $A W$, while those with fewer financial assets, including households with zero financial assets, have a greater probability of choosing Cash only. This is consistent with the partial relationship in the bottom panel of Fig. 2. Higher financial literacy as measured by the

\footnotetext{
17 We refer interested readers to Tables 11 and 12 in the appendix for the estimates of the multinomial logit parameters generating the marginal effects.
} 


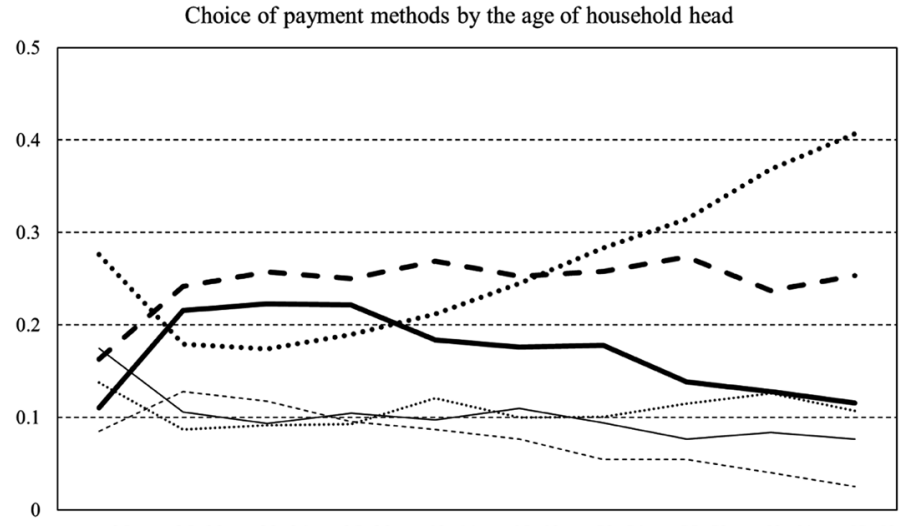

age -25 age 25-29age 30-34age 35-39age 40-44age 45-49age 50-54age 55-59age 60-64age 65-69 —Cash only -... Card \& Cash …... Cash \& AW - Card only - Card \& AW ....AW only

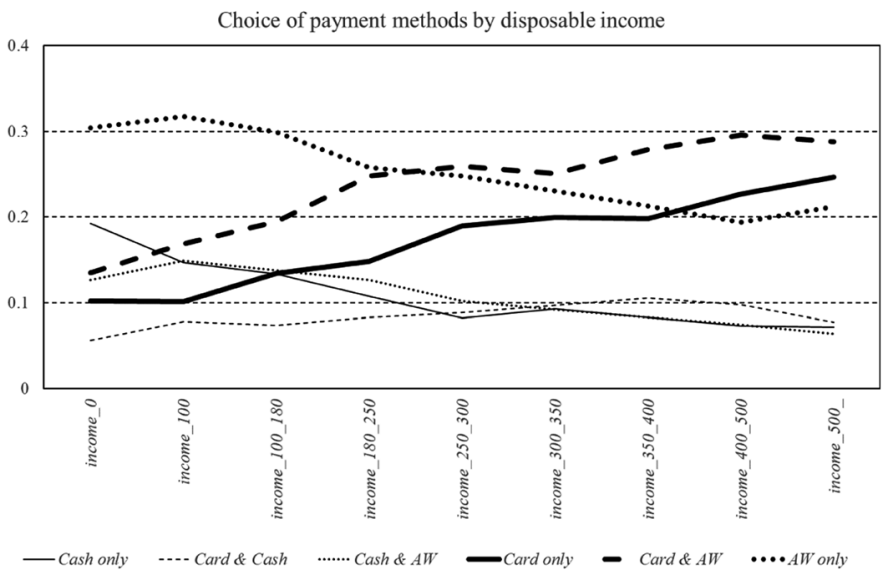

Choice of payment methods by the amount of finanial assets

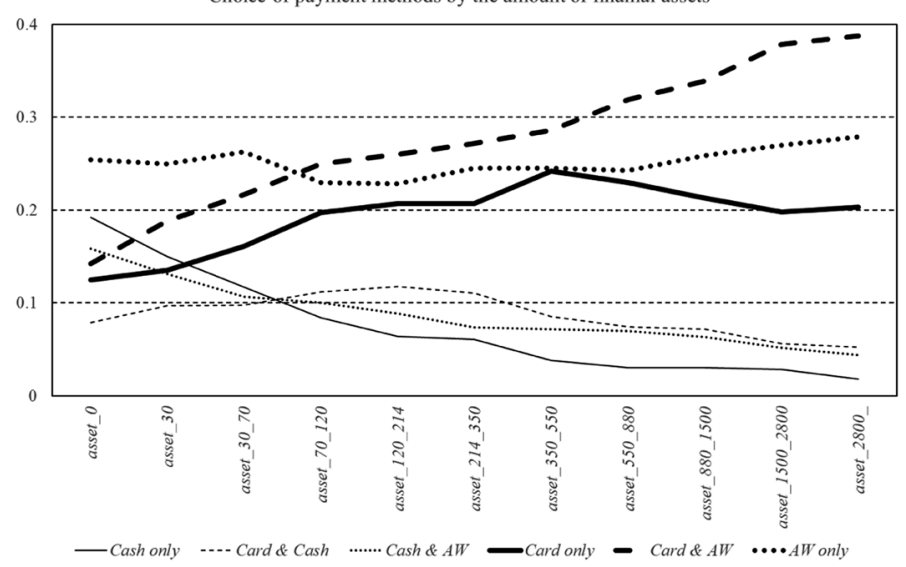

Fig. 3 Choice of payment method by the age of household head, disposable income, and financial asset holdings: single-person households 


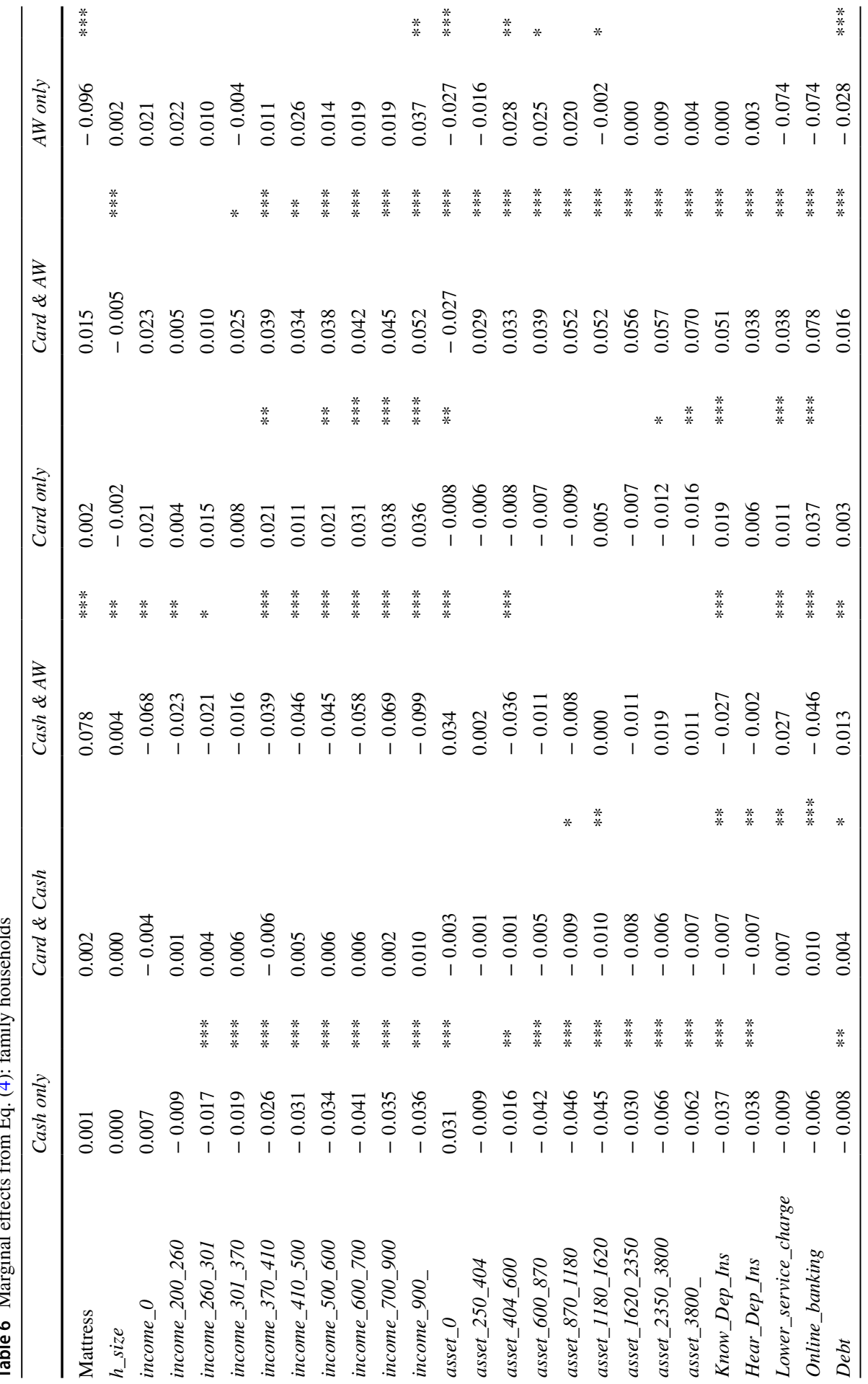




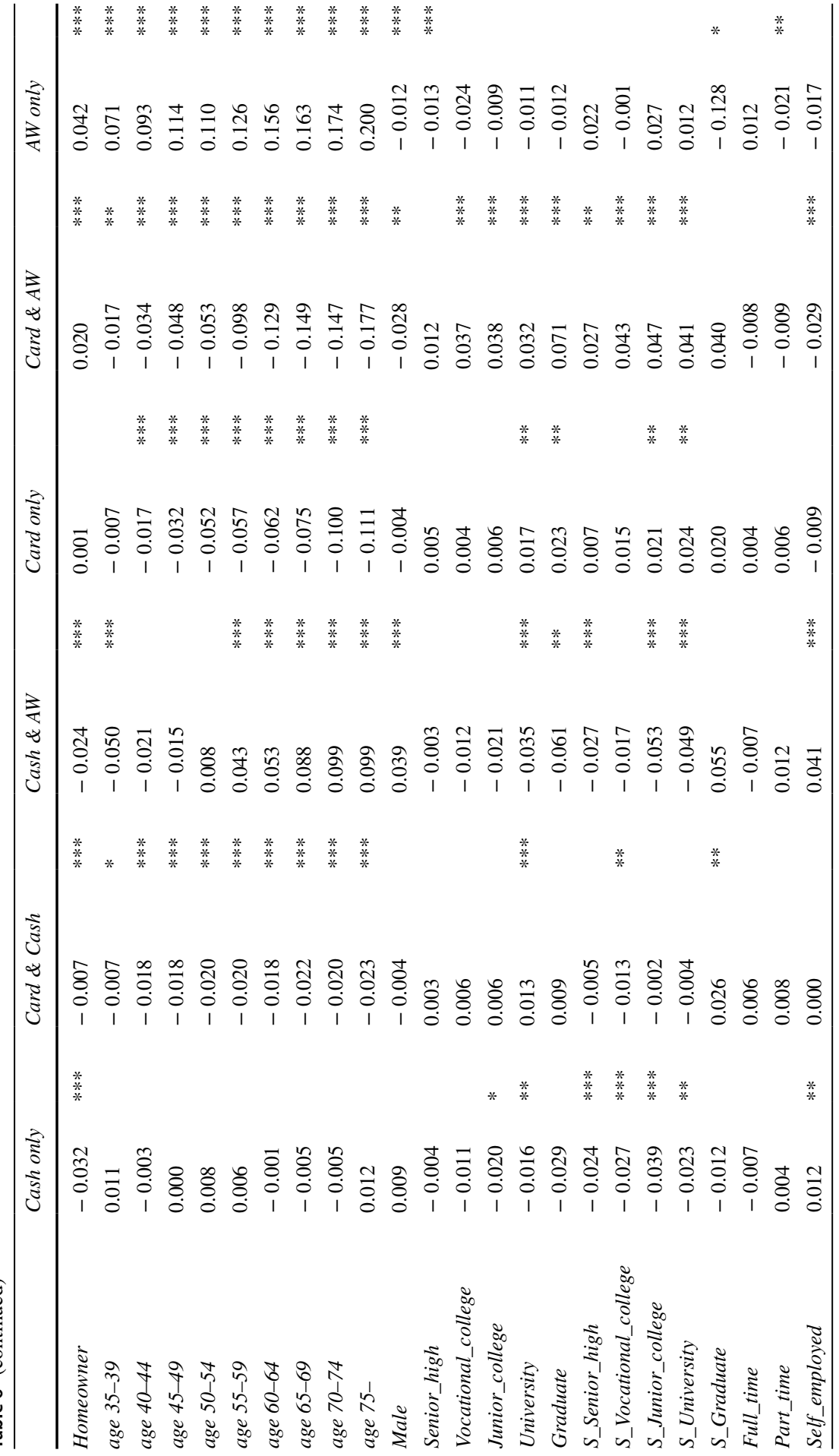




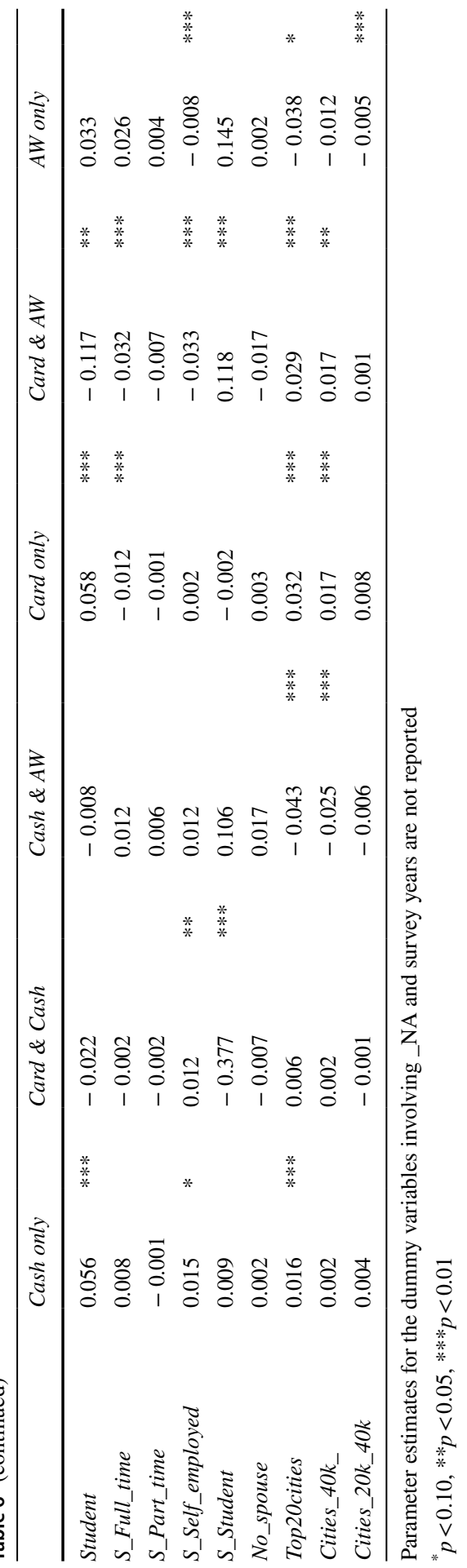




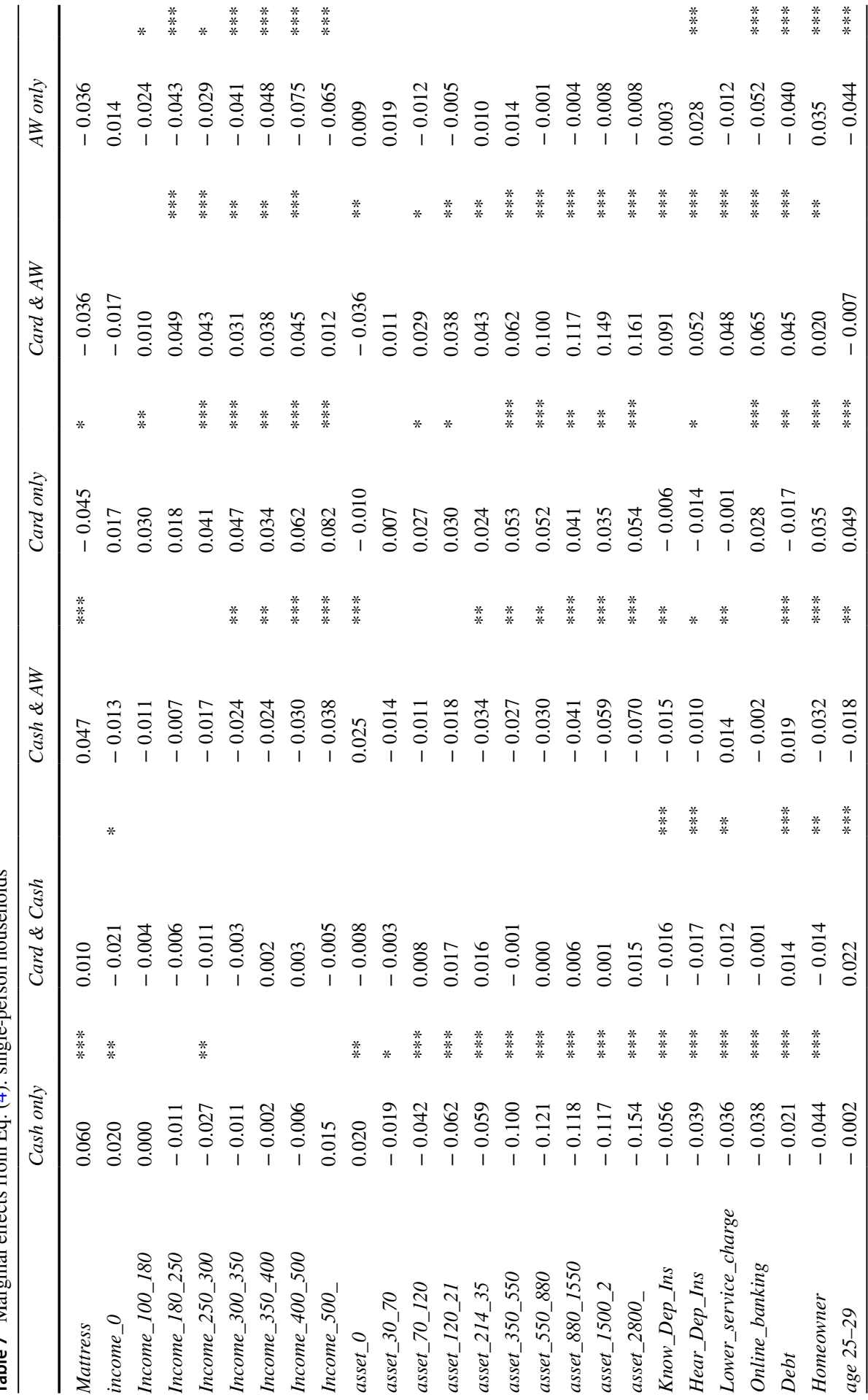




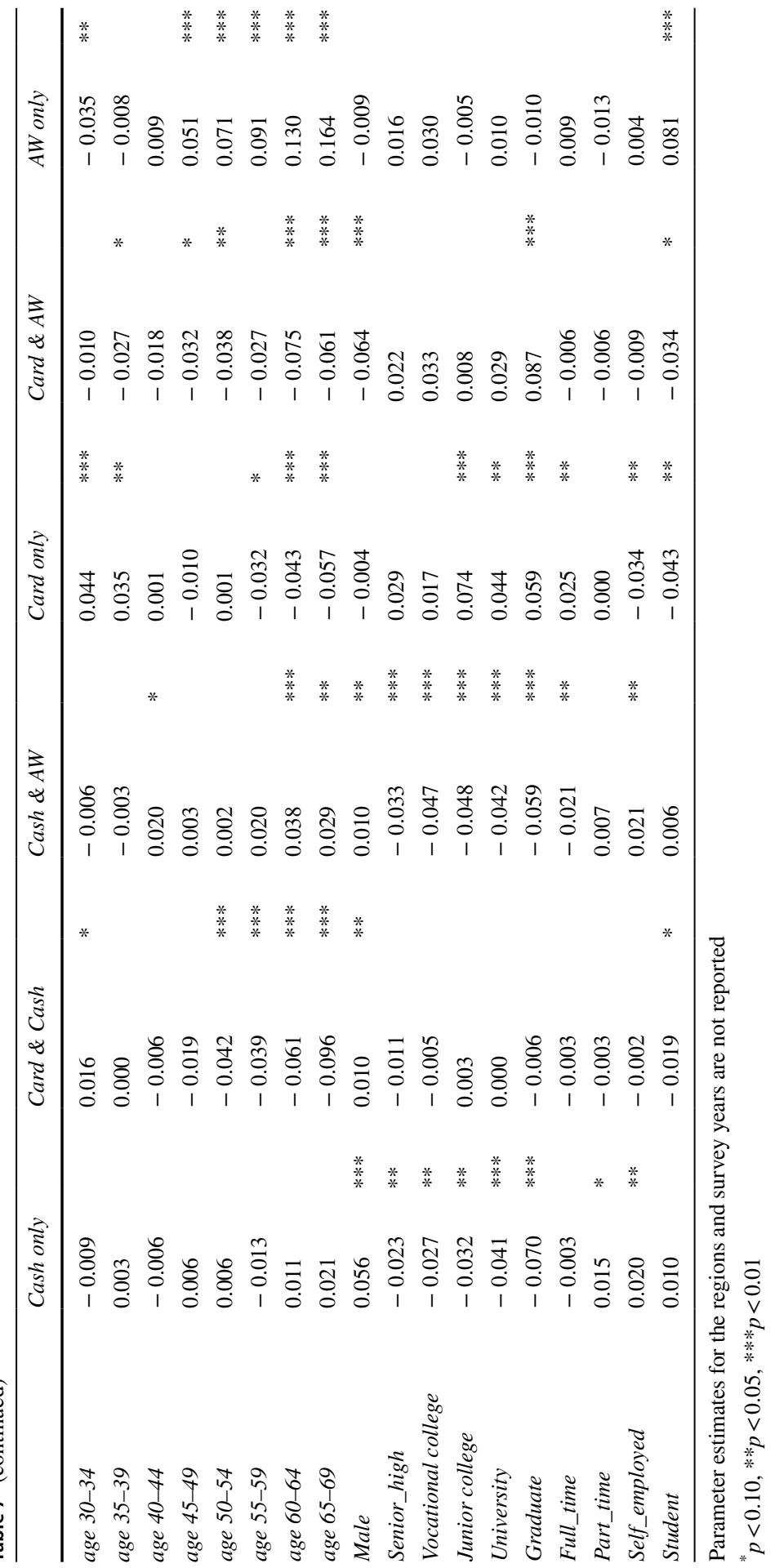


knowledge of deposit insurance (Know_Dep_Ins) increases the probability of choosing Card only and Card \& $A W$.

Households that place an emphasis on online banking services (Online_Banking) and lower service charges in selecting financial institutions (Lower_service_charge), and those with a university graduate (University) head are more likely to have choices involving Card. Households with a young household head are more likely to choose Card \& Cash, Card only, and Card \& $A W$, whereas an older household head is more likely associated with Cash \& $A W$ and $A W$ only, which is consistent with the partial relationship observed in the top panel of Fig. 2. Households with self-employed heads are more likely to choose Cash only and Cash \& AW, rather than those choices involving Card. These results are consistent with the findings in Fujiki and Tanaka (2018a, b) for households choosing card_ $d$ and cash only_ $d$ for day-to-day payment methods. Nonetheless, we also provide detailed information about $A W$ in this analysis.

Table 7 reports the results for single-person households. As we are interested in the increase in the choice of Cash only, we consider the results for this group first. The dummy variable for zero income is positive and significant, while the dummy variable for income between 2.5 million yen and 3.0 million yen is negative and statistically significant for this group. Those households tend to have no or few financial assets, lower financial literacy, and only a small interest in the service provided by banks, which seems to be consistent with their preference for Cash only. They also tend to have male, self-employed or part-time worker household heads and household heads with lower educational levels.

Regarding the results for the remaining choices, households with more disposable income have a greater probability of choosing Card only and Card \& $A W$, while those with less disposable income have a greater probability of choosing Cash \& $A W$ and $A W$ only. Households with more financial assets also have a higher probability of choosing Card \& $A W$ and Card only, while those with fewer financial assets have an increased likelihood of choosing Cash \& $A W$. Higher financial literacy as measured by knowledge of deposit insurance is associated with the greater likelihood of choosing Card \& $A W$, while households placing an emphasis on online banking services and lower service charges when selecting a financial institution or with a graduate head tend to choose $C$ ard \& $A W$.

Households with a young household head have a greater probability of choosing Card \& Cash, Card only, and Card \& AW, while older household heads have a higher probability of choosing Cash \& $A W$ and $A W$ only. Overall, these findings suggest that the key factor separating the choices of Card and $A W$ is the age of the household head, except for the choice of Cash only. In Fujiki and Tanaka (2018a), age was also a key variable determining the choice of $c a s h$ only_ $d$ or $c a r d \_$, even though age was not particularly related to the choice of Cash only for regular payments. 


\section{Demand for cash}

We have documented the increasing popularity of Card and the decreasing popularity of $A W$ in regular payments. Is this trend associated with the increasing or decreasing demand for cash by Japanese households? It would of course be difficult to respond to this question if there is some new technology that would reduce the choice of cash for regular payments substantially; for example, the prevalence of QR code applications linked to bank accounts. Hence, we assume that the current gradual pace of adopting noncash payment methods will continue. One way to see the effect shifting from $A W$ to Card in the family household data would be to compare the cash holdings of $A W$ only, Cash \& $A W$, and Cash only with those of Card \& $A W$, Card only, and Card \& Cash. We would then examine the hypothetical changes in cash holdings if the shift from the first group to the second group took place. Let us take $A W$ only, Cash \& $A W$, and Cash only as control groups, and Card \& AW, Card only, and Card \& Cash as treated groups, and examine the changes in the demand for cash across these two groups. In the single-person household data, by similar reasoning, we take $A W$ only, Cash \& $A W$, and Card \& $A W$ as control groups, and Card only, Cash only, and Card \& Cash as treated groups. We compute the changes in the demand for cash in two ways. The first method is to estimate the conditional cash demand function (2) and simulate the demand for cash by each choice of payment method. The second method is the application of a matching technique to the two groups. We discuss both methods in turn.

Regarding the first method, we first estimate the conditional cash demand function (2), assuming that the coefficient of demand for cash, $\beta_{j}$, other than the correction terms, is the same for all $j$, and only $R(j)_{k}$ differs across $k$. We estimate Eq. (5) using the STATA 14 command reg:

$$
\begin{aligned}
& \left(\bar{C}_{i j t} \mathrm{lj} \text { chosen }\right)=X_{i j t} \beta+(\sigma \sqrt{6} / \pi) \sum_{k=1}^{6} R(j)_{k} Z_{i j t}+u_{i j t}, \\
& Z_{i j t}=-\log P_{i k t} \text { if } k=j, Z_{i j t}=\left(P_{i k t} /\left(1-P_{i k t}\right)\right) \log P_{i k t} \text { if } k \neq j .
\end{aligned}
$$

We use a formula from Dubin (1982, Theorem 1, T1h, p. 312) to compute the standard errors of the parameter estimates of Eq. (5). We then use the fitted values for Eq. (5) to estimate the difference in the cash holdings by the choice of payment method.

Table 8 shows the parameter estimates (columns labeled "Parameters") and their standard errors (columns labeled "S.E.") of the demographic variables for both family and single-person households. The mattress deposit dummies are positive and statistically significant. Respondents in higher categories of disposable income and 
Table 8 Parameter estimates for Eq. (5): demographic variables

\begin{tabular}{|c|c|c|c|c|c|c|c|}
\hline \multicolumn{4}{|l|}{ Family household data } & \multicolumn{4}{|c|}{ Single-person household data } \\
\hline Independent variables & Parameter & & S.E & Independent variables & Parameter & & S.E \\
\hline Mattress & 23.294 & $* * *$ & 2.337 & Mattress & 26.218 & $* * *$ & 5.567 \\
\hline$h \_s i z e$ & -0.190 & & 0.235 & & & & \\
\hline income_O & -1.788 & & 3.455 & income_O & 1.245 & & 3.152 \\
\hline income_200_260 & 0.071 & & 1.317 & income_100_180 & -2.027 & & 2.429 \\
\hline income_260_301 & 0.560 & & 1.381 & income_180_250 & -1.169 & & 2.508 \\
\hline income_301_370 & 0.708 & & 1.557 & income_250_300 & -1.553 & & 3.208 \\
\hline income_370_410 & 1.396 & & 1.642 & income_300_350 & 2.974 & & 3.098 \\
\hline income_410_500 & -0.154 & & 1.806 & income_350_400 & 4.209 & & 3.261 \\
\hline income_500_600 & 2.198 & & 1.683 & income_400_500 & 4.522 & & 3.658 \\
\hline income_600_700 & 3.278 & $*$ & 1.848 & income_500_ & 16.470 & $* * *$ & 4.168 \\
\hline income_700_900 & 4.642 & $* *$ & 1.828 & & & & \\
\hline income_900_ & 10.140 & $* * *$ & 2.042 & & & & \\
\hline asset_0 & 1.320 & & 1.343 & asset_0 & 2.822 & & 2.728 \\
\hline asset_250_404 & 1.947 & & 1.263 & asset_30_70 & 2.445 & & 2.978 \\
\hline asset_404_600 & 3.931 & $* * *$ & 1.484 & asset_70_120 & 3.265 & & 3.301 \\
\hline asset_600_870 & 5.858 & $* * *$ & 1.674 & asset_120_214 & 6.129 & & 3.744 \\
\hline asset_870_1180 & 2.950 & & 1.850 & asset_214_350 & 10.033 & $* *$ & 4.069 \\
\hline asset_1180_1620 & 3.976 & $* *$ & 1.763 & asset_350_550 & 7.951 & $*$ & 4.702 \\
\hline asset_1620_2350 & 5.790 & $* * *$ & 1.669 & asset_550_880 & 12.898 & $* *$ & 5.178 \\
\hline asset_2350_3800 & 7.582 & $* * *$ & 2.018 & asset_880_1500 & 13.477 & $* *$ & 5.341 \\
\hline \multirow[t]{2}{*}{ asset_3800_ } & 17.563 & $* * *$ & 2.081 & asset_1500_2800 & 17.258 & $* * *$ & 5.961 \\
\hline & & & & asset_2800_ & 20.988 & $* * *$ & 6.473 \\
\hline Know_Dep_Ins & 1.328 & & 1.479 & Know_Dep_Ins & -6.717 & $* *$ & 3.122 \\
\hline Hear_Dep_Ins & -0.570 & & 1.445 & Hear_Dep_Ins & -4.025 & & 2.672 \\
\hline Lower_service_charge & -1.197 & & 1.171 & Lower_service_charge & -7.478 & $* * *$ & 2.067 \\
\hline Online_banking & 2.940 & $*$ & 1.628 & Online_banking & -4.587 & $* *$ & 1.997 \\
\hline Debt & -1.450 & $* *$ & 0.695 & Debt & -8.536 & $* * *$ & 2.288 \\
\hline Homeowner & 0.189 & & 1.223 & Homeowner & 3.730 & & 2.984 \\
\hline age $35-39$ & -0.911 & & 1.579 & age $25-29$ & -0.241 & & 3.281 \\
\hline age $40-44$ & -0.788 & & 1.989 & age 30-34 & -4.814 & & 3.022 \\
\hline age $45-49$ & -1.549 & & 2.077 & age $35-39$ & -2.614 & & 2.697 \\
\hline age $50-54$ & -0.545 & & 2.246 & age $40-44$ & -6.178 & $* *$ & 2.841 \\
\hline age 55-59 & -0.036 & & 2.443 & age $45-49$ & -5.039 & & 3.428 \\
\hline age 60-64 & 1.759 & & 2.655 & age 50-54 & -1.395 & & 4.210 \\
\hline age $65-69$ & 3.692 & & 3.071 & age $55-59$ & -2.095 & & 4.554 \\
\hline age $70-74$ & 3.223 & & 3.211 & age 60-64 & 0.703 & & 5.610 \\
\hline age $75-$ & 4.525 & & 3.370 & age 65-69 & 7.435 & & 7.003 \\
\hline Male & 2.934 & $*$ & 1.530 & Male & 6.807 & $* * *$ & 2.347 \\
\hline Senior_high & -1.125 & & 1.007 & Senior_high & -8.149 & $* *$ & 3.818 \\
\hline Vocational_college & -2.260 & & 1.474 & Vocational_college & -5.511 & & 4.292 \\
\hline Junior_college & -0.251 & & 1.794 & Junior_college & -8.348 & $*$ & 4.756 \\
\hline
\end{tabular}


Table 8 (continued)

\begin{tabular}{|c|c|c|c|c|c|c|c|}
\hline \multicolumn{4}{|l|}{ Family household data } & \multicolumn{4}{|c|}{ Single-person household data } \\
\hline Independent variables & Parameter & & S.E & Independent variables & Parameter & & S.E \\
\hline University & -2.891 & $* *$ & 1.450 & University & -7.560 & $*$ & 4.124 \\
\hline Graduate & -4.907 & $* *$ & 2.305 & Graduate & -8.497 & & 5.332 \\
\hline S_Senior_high & 0.098 & & 1.317 & & & & \\
\hline S_Vocational_college & 0.800 & & 1.765 & & & & \\
\hline S_Junior_college & 0.299 & & 1.717 & & & & \\
\hline S_University & 1.314 & & 1.698 & & & & \\
\hline S_Graduate & 1.696 & & 4.918 & & & & \\
\hline Full_time & -0.353 & & 1.029 & Full_time & -1.191 & & 2.332 \\
\hline Part_time & -1.251 & & 1.314 & Part_time & -0.144 & & 2.210 \\
\hline Self_employed & 4.017 & $* * *$ & 1.198 & Self_employed & 4.998 & $*$ & 2.647 \\
\hline Student & 17.527 & $* * *$ & 5.341 & Student & 0.377 & & 3.575 \\
\hline S_Full_time & -1.452 & & 0.954 & & & & \\
\hline S_Part_time & -1.551 & $* *$ & 0.732 & & & & \\
\hline S_Self_employed & 2.169 & & 1.593 & & & & \\
\hline S_Student & 1.914 & & 7.638 & & & & \\
\hline No_spouse & 4.004 & $* *$ & 1.650 & & & & \\
\hline R-square adjusted & & & 0.045 & & & & 0.045 \\
\hline Number of observations & & & 29,031 & & & & 19,249 \\
\hline
\end{tabular}

Parameter estimates for the dummy variables involving _NA, regions, and survey years are not reported ${ }^{*} p<0.10, * * p<0.05, * * * p<0.01$

with more financial assets tend to have larger cash holdings in many cases. Households with a male or a self-employed head also tend to have larger cash holdings. While these findings are similar to those of Fujiki and Tanaka (2018a), unlike their analysis we also reveal that the age of the household head is not statistically significant except for 40-44 years in the single-person household data.

Table 9 details the estimates of the coefficients and their standard errors for the selection correction terms in Eq. (5). Some coefficients are now statistically significant, so we need to take care to infer the difference in the demand for cash by the choice of payment method. We report the results of our simulation using Eq. (5) in Table 10. The upper panel provides the results for the family household data, and the lower panel for the single-person household data. The rows labeled "Case number" assign a value from 1 to 9 for the combination of the control group, $A W$ only, Cash \& $A W$, and Cash only for the family household data and $A W$ only, Cash \& $A W$, 
Table 9 Parameter estimates for Eq. (5): sample selection adjustment terms

\begin{tabular}{|c|c|c|c|c|c|c|}
\hline & \multicolumn{3}{|c|}{ Family household data } & \multicolumn{3}{|c|}{ Single-person household data } \\
\hline & Parameter & & S.E & Parameter & & S.E \\
\hline$R$ (Cash only)Cash only & 0.309 & $* *$ & 4.365 & 0.329 & $*$ & 9.093 \\
\hline$R($ Cash only)Card \& Cash & -1.479 & & 41.776 & 0.876 & & 52.290 \\
\hline$R($ Cash only $)$ Cash \& $A W$ & 1.178 & $* *$ & 18.577 & -0.138 & & 36.905 \\
\hline$R$ (Cash only) Card only & 0.206 & & 34.230 & -1.112 & & 43.079 \\
\hline$R($ Cash only $)$ Card \& $A W$ & 1.671 & $*$ & 29.670 & 0.746 & & 46.719 \\
\hline$R($ Cash only $) A W$ only & -0.012 & & 17.820 & 0.489 & & 26.446 \\
\hline$R($ Card \& Cash $)$ Cash only & 0.335 & & 11.462 & 0.515 & & 16.896 \\
\hline$R($ Card \& Cash)Card \& Cash & -0.060 & & 1.851 & 0.147 & & 4.359 \\
\hline$R($ Card \& Cash $)$ Cash \& AW & 0.367 & & 13.379 & -0.572 & & 22.165 \\
\hline$R($ Card \& Cash)Card only & -0.203 & & 13.333 & -0.810 & $* *$ & 16.307 \\
\hline$R($ Card \& Cash $)$ Card \& AW & 0.315 & & 11.744 & 0.507 & & 16.365 \\
\hline$R($ Card \& Cash $) A W$ only & -0.743 & $* *$ & 9.321 & 0.559 & $*$ & 15.351 \\
\hline$R($ Cash \& AW)Cash only & 0.256 & & 5.154 & 0.068 & & 9.644 \\
\hline$R($ Cash \& AW)Card \& Cash & -0.287 & & 9.044 & 0.046 & & 16.936 \\
\hline$R($ Cash \& AW)Cash \& $A W$ & 0.043 & & 1.596 & -0.107 & $*$ & 2.756 \\
\hline$R($ Cash \& AW)Card only & 0.287 & & 7.287 & -0.493 & & 14.320 \\
\hline$R($ Cash \& $A W)$ Card \& $A W$ & 0.048 & & 4.669 & -0.255 & & 10.178 \\
\hline$R($ Cash \& AW)AW only & 0.037 & & 3.618 & -0.194 & & 7.495 \\
\hline$R($ Card only)Cash only & 0.119 & & 5.501 & 0.039 & & 8.169 \\
\hline$R($ Card only $)$ Card \& Cash & -0.164 & & 7.418 & 0.019 & & 10.245 \\
\hline$R($ Card only $)$ Cash \& $A W$ & -0.019 & & 6.383 & -0.510 & $* *$ & 10.504 \\
\hline$R($ Card only $)$ Card only & -0.006 & & 0.687 & -0.095 & $*$ & 2.366 \\
\hline$R($ Card only $)$ Card \& $A W$ & 0.134 & & 3.109 & -0.156 & & 6.317 \\
\hline$R($ Card only $) A W$ only & -0.047 & & 3.238 & -0.135 & & 5.991 \\
\hline$R($ Card \& AW)Cash only & -0.017 & & 3.643 & 0.228 & $*$ & 6.209 \\
\hline$R($ Card \& AW)Card \& Cash & -0.113 & & 5.036 & 0.015 & & 8.189 \\
\hline$R($ Card \& AW)Cash \& AW & -0.044 & & 3.396 & -0.346 & $* *$ & 6.708 \\
\hline$R($ Card \& AW)Card only & 0.109 & & 2.784 & -0.097 & & 5.495 \\
\hline$R($ Card \& $A W)$ Card \& $A W$ & -0.015 & & 0.526 & 0.022 & & 1.692 \\
\hline$R($ Card \& $A W) A W$ only & 0.025 & & 1.760 & 0.083 & & 3.786 \\
\hline$R(A W$ only $)$ Cash only & 0.059 & & 2.478 & 0.119 & & 3.936 \\
\hline$R(A W$ only $)$ Card \& Cash & -0.105 & & 3.986 & 0.111 & & 6.878 \\
\hline$R(A W$ only $)$ Cash \& $A W$ & -0.041 & & 1.899 & -0.209 & $* *$ & 4.863 \\
\hline$R(A W$ only $)$ Card only & 0.004 & & 2.764 & -0.194 & $*$ & 4.894 \\
\hline$R(A W$ only $)$ Card \& $A W$ & -0.011 & & 1.816 & 0.055 & & 3.345 \\
\hline$R(A W$ only $) A W$ only & -0.046 & $*$ & 0.815 & 0.005 & & 1.224 \\
\hline
\end{tabular}

${ }^{*} p<0.10, * * p<0.05, * * * p<0.01$ 
Table 10 Differences in the demand for cash by payment choice

\begin{tabular}{|c|c|c|c|c|c|c|c|c|c|}
\hline Case number & (1) & (2) & (3) & (4) & (5) & (6) & (7) & (8) & (9) \\
\hline Control & AW only & Cash \& $A W$ & Cash only & AW only & Cash \& $A W$ & Cash only & AW only & Cash \& $A W$ & Cash only \\
\hline Treated & Card \& $A W$ & Card \& $A W$ & Card \& $A W$ & Card only & Card only & Card only & Card \& Cash & Card \& Cash & Card \& Cash \\
\hline \multicolumn{10}{|l|}{ Conditional cash demand } \\
\hline Difference in the fitted value & -3.114 & -2.425 & -1.806 & -2.694 & -2.005 & -1.386 & 1.019 & 1.707 & 2.327 \\
\hline P-value & 0.000 & 0.000 & 0.000 & 0.000 & 0.000 & 0.000 & 0.004 & 0.000 & 0.000 \\
\hline \multicolumn{10}{|l|}{ Matching } \\
\hline Psmatch ATE & $-3.242^{* * * *}$ & $-3.000^{* *}$ & $-7.179^{* * *}$ & 0.627 & 3.206 & -3.178 & $7.964 * *$ & $2.582^{* * *}$ & -3.22 \\
\hline Psmatch ATET & $-3.223^{* * *}$ & $-5.099 * * *$ & $-8.947 * * *$ & 0.909 & -1.521 & $-6.288^{*}$ & $8.441^{* *}$ & $2.547^{*}$ & -2.886 \\
\hline IPW ATE & $-2.728^{* * * *}$ & $-2.594^{* * * *}$ & $-6.064 * * *$ & -0.97 & -1.538 & $-7.205^{* *}$ & $3.826^{*}$ & 1.096 & -1.812 \\
\hline IPW ATET & $-2.851^{* * * *}$ & $-3.527^{* * *}$ & $-6.896 * * *$ & -1.105 & -1.17 & -11.537 & 3.846 & 0.915 & -1.555 \\
\hline Number of observations & 17914 & 10533 & \begin{tabular}{l|l}
6073 \\
\end{tabular} & 15472 & 8091 & 3631 & 14867 & 7486 & 3026 \\
\hline PseudoRsq & 0.145 & 0.252 & 0.367 & 0.225 & 0.324 & 0.3643 & 0.084 & 0.127 & 0.189 \\
\hline LLR & -8043.476 & -5200.596 & -2500.528 & -3778.734 & -2597.41 & -1559.504 & -3041.45 & -2352.277 & -1473.73 \\
\hline$\%$ correctly classified & $79.63 \%$ & $76.34 \%$ & $81.51 \%$ & $91.07 \%$ & $86.64 \%$ & $80.23 \%$ & $94.16 \%$ & $88.61 \%$ & $77.23 \%$ \\
\hline Area under ROC & 0.759 & 0.823 & 0.878 & 0.830 & 0.870 & 0.878 & 0.713 & 0.752 & 0.788 \\
\hline \multicolumn{10}{|l|}{ Single-person household data } \\
\hline Case number & (1) & (2) & (3) & (4) & (5) & (6) & (7) & $(8)$ & (9) \\
\hline Control & AW only & Cash \& $A W$ & Card \& $A W$ & AW only & Cash \& $A W$ & Card \& $A W$ & AW only & Cash \& $A W$ & Card \& $A W$ \\
\hline Treated & Card only & Card only & Card only & Cash only & Cash only & Cash only & Card \& Cash & Card \& Cash & Card \& Cash \\
\hline \multicolumn{10}{|l|}{ Conditional cash demand } \\
\hline Difference in the fitted value & 0.882 & 5.584 & 1.296 & -1.434 & 3.268 & -1.019 & 2.921 & 7.622 & 3.335 \\
\hline P-value & 0.002 & 0.000 & 0.000 & 0.000 & 0.000 & 0.000 & 0.000 & 0.000 & 0.000 \\
\hline \multicolumn{10}{|l|}{ Matching } \\
\hline Psmatch ATE & -1.305 & -1.937 & 0.147 & 10.197 & $4.786^{* *}$ & $11.777 * *$ & $3.522 *$ & $4.262 *$ & 2.157 \\
\hline Psmatch ATET & $-2.898^{*}$ & -3.447 & -1.181 & 17.055 & $5.815^{* *}$ & $15.847^{* *}$ & 2.293 & 4.24 & 1.134 \\
\hline IPW ATE & -1.102 & 0.267 & 0.399 & 7.659 & $4.482 * *$ & $9.018^{* *}$ & 2.965 & $4.623 * *$ & $5.972 * * *$ \\
\hline IPW ATET & -1.381 & 0.374 & 0.305 & 9.99 & $4.670^{* *}$ & $12.270^{* *}$ & 2.308 & $3.990 * *$ & $6.146^{* *}$ \\
\hline Number of observations & 8518 & 5617 & 8264 & 7163 & 4262 & 6909 & 6723 & 3822 & 6469 \\
\hline PseudoRsq & 0.117 & 0.169 & 0.042 & 0.141 & 0.075 & 0.276 & 0.111 & 0.117 & 0.082 \\
\hline LLR & -5086.983 & -3098.913 & -5388.172 & -3741.378 & -2733.763 & -3086.127 & -3366.576 & -2314.595 & -3406.063 \\
\hline$\%$ correctly classified & $68.11 \%$ & $71.68 \%$ & $61.33 \%$ & $73.82 \%$ & $62.93 \%$ & $78.77 \%$ & $75.31 \%$ & $67.24 \%$ & $74.37 \%$ \\
\hline Area under ROC & 0.726 & 0.771 & 0.637 & 0.749 & 0.678 & 0.840 & 0.728 & 0.725 & 0.697 \\
\hline
\end{tabular}

and Card \& $A W$ for the single-person household data, and our treated group, Card $\& A W$, Card only, and Card \& Cash for the family household data and Card only, Cash only, and Card \& Cash for the single-person household data. Cases 1 to 3, 4 to 6, and 7 to 9 consider Card \& AW, Card only, and Card \& Cash for the family household data and Card only, Cash only, and Card \& Cash for the single-person household data as the treated groups, respectively. The rows labeled "Differences in the fitted value" report the difference in the mean cash holdings conditional on the choice of payment methods using the estimates from Eq. (5). The rows labeled "P-value" are the $p$ values of the $t$ test of statistical significance of the difference in the mean cash holdings. These rows show statistically significant differences in the mean predicted cash holdings and are, in most cases, significant at the $0.0 \%$ level (the exceptions are case (7) for the family household data and case (1) for singleperson household data where the $p$ values are $0.4 \%$ and $0.2 \%$, respectively). 
We may wish to use these differences to consider the effects of the changes in the decreasing choice involving $A W$ and increasing choice involving Card on the conditional cash demand. However, these results could be biased from misspecification in the conditional cash demand function. Therefore, we double check the results by estimating the ATEs and ATETs of the choice of treated groups rather than the control groups using propensity score matching and inverse probability weighting techniques, as these are independent of the specification of the conditional demand for cash. We use the commands psmatch and ipw in STATA14 to perform our estimations. We run the following logistic treatment model regression Eq. (6) using the subsamples of households $i$ choosing the $j$ th payment methods and households $i$ choosing the $j+1$ payment methods:

$$
D_{i j(j+1) t}=X_{i j(j+1) t} \theta_{j(j+1)}+v_{i t}, j=1, \ldots, 6, j+1 \leq 6,
$$

where $D_{i j(j+1) t}$ is an indicator variable that takes a value of zero for household $i$ choosing the $j$ th payment methods and one for household $i$ choosing $j+1$ at time $t, X_{i j(j+1) t}$ is a vector of the same demographic variables used in Tables 6 and $7, \theta_{j(j+1)}$ is a vector of parameters to be estimated, and $v_{i t}$ is a disturbance term. We select the combinations of $j$ and $j+1$ that fit the combinations of our control and treated groups listed in cases (1) through (9) in Table 10. If some demographic variables have an absolute value of standardized difference after matching of more than 0.1 , we drop the demographic variable with the largest absolute value of the standardized difference and match again using the remaining common covariates as explanatory variables. We continue this process until all the absolute values of the standardized differences after matching are less than 0.1 .

The estimation results are shown in Table 10, starting from the rows labeled "Matching." The rows labeled "Psmatch ATE" and "Psmatch ATET" show the ATE and ATET estimated by the propensity score matching method, and the rows labeled "IPW ATE" and "IPW ATET" show the ATE and ATET estimated by the inverse probability weighting method. The rows labeled "Number of observations" provide the sample size for each logistic treatment model. The remaining rows (headings in brackets) show goodness-of-fit statistics for the logistic treatment model, including the pseudo $\mathrm{R}^{2}$ (PseudoRsq), the log-likelihood ratio (LLR), the percentage of observations correctly classified (\% correctly classified), and the area under the receiver-operating characteristic curve (Area under ROC).

Regarding the family household results, the upper panel of Table 10 indicates that the ATEs and ATETs are negative and statistically significant when we take $A W$ only, Cash \& $A W$, and Cash only as control groups and Card \& $A W$ as treated groups [Cases (1) through (3)], and when we specify Cash only as the control group and Card only as the treated group [Case (6)], except for Psmatch ATE and IPW ATET for case (6). The ATEs and ATETs are positive and statistically significant when we specify $A W$ only and Cash \& $A W$ as the control group and Card $\&$ Cash as the treated group [Cases (7) and (8)], except for the IPW ATET for case (7), and IPW ATE and IPW ATET for case (8). 
Regarding the single-person household results, the lower panel of Table 10 indicates the Psmatch ATET is negative and statistically significant when we take $A W$ only as the control group and Card only as the treated group [Case (1)]. The ATEs and ATETs are positive and statistically significant when we choose Cash $\& A W$ and $C$ ard \& $A W$ as control groups and Cash only as treated groups [Cases (5) and (6)]. The Psmatch ATEs are positive and statistically significant when we take $A W$ only and Cash \& $A W$ as control group and Card \& Cash as treated group [Cases (7) and (8)]. The IPW ATEs and ATETs are positive and statistically significant when we take Cash \& $A W$ and Card \& $A W$ as control group and Card \& Cash as treated group [Cases (8) and (9)].

As we ran these estimations as a robustness check for the results obtained from Eq. (5), we focus on the cases in the shaded area where the signs of the statistically significant ATEs and ATETs are consistent with the difference of the mean obtained from Eq. (5). In the models in the shaded area, the goodness-of-fit statistics for these logistic treatment models suggest that those models are effective in distinguishing between the control and treated groups. This is because the test statistics reported in the rows labeled "Area under ROC" have values from 0.6 to 0.9 and those reported in rows labeled "\% correctly classified" have values from 60 to $90 \%$.

Focusing on the models in the shaded area, we surmise the impact of the increasing choice of Card and the decreasing choice of $A W$ for regular payments under the current gradual pace of adopting noncash payment methods. First, for the family households, cases (1) through (3) and case (6) suggest that the impact of the increasing choice of Card and the decreasing choice of $A W$ for regular payments, if continued as a shift towards Card \& $A W$ and Card only, would be associated with a decreasing demand for cash. However, cases (7) and (8) suggest that the shift towards Card \& Cash would be associated with the increasing demand for cash. From 2007 to 2014 , the increase in the number of households choosing Card \& $A W$ and Card only exceeded the increase in the number of households choosing Card \& Cash. Accordingly, we conclude that the increasing choices involving Card and decreasing choices involving $A W$ are associated with the decreasing demand for cash. Second, in the case of single-person households, the transitions to Cash only [case (5)] and Card \& Cash [cases (7) through (9)] are both associated with the increasing demand for cash. This lies contrary to the results for the family households.

\section{Conclusion and reservations}

We used SHF family and single-person household data sets from 2007 to 2014 and obtained the following results. First, the six major payment methods for regular payment are Cash only, Card \& Cash, Cash \& AW, Card only, Card \& $A W$, and $A W$ only. In the family household data, the top three choices, accounting for $85 \%$ of all observations, are $A W$ only, Cash \& $A W$, and Card \& $A W$. Clearly, all include $A W$. However, the proportion of households choosing $A W$ only and Cash \& $A W$ decreases over time, whereas the proportion of households choosing Card increases over time. In the single-person household data, the popularity of choices involving $A W$, 
which accounts for $62 \%$ of total observations, is also decreasing. The popularities of choices of Card only, Card \& Cash, and, surprisingly, Cash only are increasing.

Given those observations, we posed two questions. First, what household characteristics are associated with the choice of Card and $A W$ for making regular payments in both data sets, and the choice of Cash only in the single-person household data set? Using a multinomial logit model, we found that households with a younger household head tended to make choices involving Card. We also found that households with more disposable income and financial assets chose Card \& $A W$. Regarding the single-person households who chose Cash only, these households tended to have fewer financial assets, lower financial literacy as measured by knowledge about the Deposit Insurance Corporation of Japan, less interest in the services provided by banks, and had male, self-employed or part-time worker household heads and lower educational levels.

Second, are the decreasing popularity of choices involving $A W$ and the increasing popularity of choices involving Card in both data sets and that of Cash only in the single-person households associated with the increasing or decreasing demand for cash? To answer this question, we compared the demand for cash by the groups of increasingly popular and unpopular payment choices in two ways. First, we simulated the estimates of a conditional cash demand function, and second, we used two matching techniques. We found that recent changes in the popularity of the choice of regular payment methods are associated with the decreasing demand for cash in family households and the increasing demand for cash in single-person households, assuming that the current gradual pace of adopting noncash payment methods continues.

It is unclear to what extent the counter-intuitive result from the single-person data set could be attributable to the fact that it is from a sample of persons aged less than 70 years and who are willing to participate in a web survey. Notwithstanding these limitations, the results suggest that we should seriously address the declining choice of $A W$ and the increasing choice of Cash only (a likely one for a household with less disposable income and financial assets, visiting convenience stores frequently) and Card \& Cash (likely for households with a relatively young household head) in any policy discussion. For example, the METI will subsidize cashless payments in some registered retail shops for 9 months after October 1, 2019 and plans to increase the cashless payment ratio from 20 to $40 \%$ by $2025 .{ }^{18}$ However, our findings suggest that if such a policy were to lead to an increase in the popularity of Card \& Cash under the current gradual pace of adopting noncash payment methods, it could paradoxically result in a society with more cash usage, and one contrary to METI's policy intent.

The major limitation of the analysis is that we assume that the current gradual pace of adopting noncash payment methods will continue. With the rapid adoption of noncash payment methods, our analysis may not be as applicable to contemporary policy discussion. For example, we argued that the innovations made by convenience stores in accepting bill payment by cash on behalf of utility companies increased the benefits of using cash to make regular payments, and thereby assisted those preferring to visit convenience stores frequently. In turn, some of the other recent innovations in convenience stores could reduce the choice of using cash for bill payment,

${ }^{18}$ For details of METI's “cashless vision”, see https://www.meti.go.jp/english/press/2018/0411_002. html. 
thanks to the prevalence of smartphone applications. For example Lawson, one of the three largest convenience store chains in Japan, accepts bill payment for some power supply companies, including Tokyo Electric Power Company, using smartphone applications such as LINE, a social networking service (SNS) application that allows person-to-person payments linked to the user's bank account. ${ }^{19}$ If such services were to prevail, some people could switch from Cash only to smartphonebased bank account transfers when making regular payments. As another example, the major banks started issuing branded debit cards in 2013, such that by the end of 2017, as many as 46 banks in Japan were issuing branded debit cards, with the volume of transactions made by branded debit cards increasing substantially. While the issue of branded debit cards could reduce the profits of banks from their ATM networks, Japanese banks already find it difficult to cover the costs of providing cash, branches, and ATMs because of the continual low or negative interest rate policy and the decrease in the number of customers visiting branches given population aging. Therefore, Japanese banks have every reason to encourage their depositors to use Internet banking and branded debit cards instead of ATM cards. If branded debit cards were to prevail, some households could then potentially switch from Cash only to Card \& Cash or Card only when making regular payments.

Acknowledgements The author would like to thank two anonymous referees, Etsuro Shioji, Juan Carlos Cuestas, Heng Chen, Ben Fung, Kim P. Huynh, Angelika Welte, and participants at the International Network For Economic Research (INFER) 2018 20th Annual Conference and the Bank of Canada Retail Payments Workshop for their useful comments and suggestions. The author would also like to thank Migiwa Tanaka for her collaboration in a companion paper. While undertaking this research, the author participated in the Research Group on the Survey of Household Finances and received permission from the Central Council for Financial Services Information to use the survey data obtained, for which the author is most grateful. The author also acknowledges the financial support of the Japan Society for the Promotion of Science through KAKENHI Grants No. 15K03551 and No. 18K01704, and the Tokyo Center for Economic Research.

Open Access This article is licensed under a Creative Commons Attribution 4.0 International License, which permits use, sharing, adaptation, distribution and reproduction in any medium or format, as long as you give appropriate credit to the original author(s) and the source, provide a link to the Creative Commons licence, and indicate if changes were made. The images or other third party material in this article are included in the article's Creative Commons licence, unless indicated otherwise in a credit line to the material. If material is not included in the article's Creative Commons licence and your intended use is not permitted by statutory regulation or exceeds the permitted use, you will need to obtain permission directly from the copyright holder. To view a copy of this licence, visit http://creativecommons.org/licen ses/by/4.0/.

\section{Appendix}

See appendix Tables 11 and 12.

\footnotetext{
${ }^{19}$ For details of line pay, see https://line.me/en/pay. Bill payment service information in Japanese is available at https://line.me/ja/pay/merchant/invoiceline\#md_card (Accessed March 31, 2019).
} 
Table 11 Results for multinomial logit estimation (4): family households

\begin{tabular}{|c|c|c|c|c|c|}
\hline Base: AW only & Cash only & Card \& Cash & Cash \& AW & Card only & Card \& AW \\
\hline Mattress & 0.224 & 0.261 & $0.552 * * *$ & 0.24 & $0.312 *$ \\
\hline$h \_s i z e$ & 0.005 & -0.011 & 0.018 & $-0.049 *$ & $-0.053 * * *$ \\
\hline income_O & 0.034 & -0.155 & $-0.361^{*}$ & 0.459 & 0.194 \\
\hline income_200_260 & $-0.185^{*}$ & -0.008 & $-0.156^{* *}$ & 0.058 & 0.012 \\
\hline income_260_301 & $-0.280 * * *$ & 0.147 & $-0.128^{*}$ & 0.334 & 0.096 \\
\hline income_301_370 & $-0.280 * *$ & 0.231 & -0.076 & 0.243 & $0.245^{*}$ \\
\hline income_370_410 & $-0.419 * * *$ & -0.182 & $-0.216^{* * * *}$ & $0.499 * *$ & $0.354 * * *$ \\
\hline income_410_500 & $-0.535^{* * *}$ & 0.156 & $-0.281^{* * *}$ & 0.27 & $0.279 * *$ \\
\hline income_500_600 & $-0.556^{* * *}$ & 0.22 & $-0.254 * * *$ & $0.511 * *$ & $0.351 * * *$ \\
\hline income_600_700 & $-0.664^{* * *} *$ & 0.223 & $-0.330 * * *$ & $0.727 * * *$ & $0.394 * * *$ \\
\hline income_700_900 & $-0.586^{* * *}$ & 0.098 & $-0.381 * * *$ & $0.882 * * *$ & $0.429 * * *$ \\
\hline income_900_ & $-0.644^{* * *}$ & 0.335 & $-0.554 * * *$ & $0.834 * * *$ & $0.460 * * *$ \\
\hline asset_o & $0.529 * * *$ & -0.053 & $0.226^{* * * *}$ & $-0.186^{*}$ & $-0.204 * * *$ \\
\hline asset_250_404 & -0.101 & 0.018 & 0.037 & -0.048 & $0.274 * * *$ \\
\hline asset_404_600 & $-0.315^{* *}$ & -0.082 & $-0.230 * * *$ & -0.168 & $0.221 * *$ \\
\hline asset_600_870 & $-0.677 * * *$ & -0.215 & $-0.118^{*}$ & -0.139 & $0.283 * * *$ \\
\hline asset_870_1180 & $-0.730 * * *$ & $-0.348^{*}$ & -0.095 & -0.17 & $0.403 * * *$ \\
\hline asset_1180_1620 & $-0.664 * * *$ & $-0.315^{*}$ & -0.017 & 0.192 & $0.461 * * *$ \\
\hline asset_1620_2350 & $-0.460 * * *$ & -0.247 & -0.069 & -0.07 & $0.474 * * *$ \\
\hline asset_2350_3800 & $-1.002 * * *$ & -0.226 & 0.041 & -0.209 & $0.459 * * *$ \\
\hline asset_3800_ & $-0.932 * * *$ & -0.216 & 0.013 & -0.256 & $0.577 * * *$ \\
\hline Know_Dep_Ins & $-0.559 * * *$ & $-0.182 *$ & $-0.146^{* * *}$ & $0.490 * * *$ & $0.478 * * *$ \\
\hline Hear_Dep_Ins & $-0.568 * * *$ & $-0.224 * *$ & -0.034 & $0.181 * *$ & $0.339 * * *$ \\
\hline Lower_service_charge & 0.017 & $0.425 * * *$ & $0.265 * * *$ & $0.448 * * *$ & $0.496 * * *$ \\
\hline Online_banking & 0.036 & $0.570 * * *$ & -0.083 & $1.121 * * *$ & $0.895 * * *$ \\
\hline Debt & -0.052 & $0.203^{* *}$ & $0.110 * * *$ & $0.155^{* *}$ & $0.207 * * *$ \\
\hline Homeowner & $-0.560 * * *$ & $-0.308 * * *$ & $-0.206^{* * *}$ & -0.039 & $0.093^{*}$ \\
\hline age 35-39 & -0.002 & $-0.398 * * *$ & $-0.369 * * *$ & $-0.316^{* * *}$ & $-0.301 * * *$ \\
\hline age $40-44$ & $-0.238 * *$ & $-0.850 * * *$ & $-0.278 * * *$ & $-0.629 * * *$ & $-0.512^{* * * *}$ \\
\hline age $45-49$ & $-0.230 *$ & $-0.913 * * *$ & $-0.289 * * *$ & $-1.040 * * *$ & $-0.705^{* * *} *$ \\
\hline age 50-54 & -0.092 & $-1.004 * * *$ & $-0.168 * *$ & $-1.496 * * *$ & $-0.781 * * *$ \\
\hline age 55-59 & -0.136 & $-1.057 * * *$ & -0.032 & $-1.709 * * *$ & $-1.213 * * *$ \\
\hline age 60-64 & $-0.281 * *$ & $-1.086^{* * *}$ & -0.039 & $-1.915 * * *$ & $-1.547^{* * *}$ \\
\hline age 65-69 & $-0.342 * *$ & $-1.277 * * *$ & 0.113 & $-2.277 * * *$ & $-1.758 * * *$ \\
\hline age $70-74$ & $-0.365^{* * *}$ & $-1.242 * * *$ & 0.141 & $-2.845^{* * * *}$ & $-1.807 * * *$ \\
\hline age 75- & -0.159 & $-1.436^{* * *}$ & 0.102 & $-3.186^{* * *}$ & $-2.136^{* * *}$ \\
\hline Male & 0.171 & -0.119 & $0.213 * *$ & -0.116 & $-0.232 * *$ \\
\hline Senior_high & -0.03 & 0.153 & 0.009 & 0.16 & 0.142 \\
\hline Vocational_college & -0.123 & 0.285 & -0.015 & 0.196 & $0.386 * * *$ \\
\hline Junior_college & $-0.284^{*}$ & 0.269 & -0.09 & 0.221 & $0.364 * * *$ \\
\hline University & $-0.226 * *$ & $0.517 * * *$ & $-0.151 * *$ & $0.470 * * *$ & $0.346^{* * * *}$ \\
\hline Graduate & -0.436 & 0.386 & $-0.281^{*}$ & $0.658 * * *$ & $0.691 * * *$ \\
\hline
\end{tabular}


Table 11 (continued)

\begin{tabular}{|c|c|c|c|c|c|}
\hline Base: AW only & Cash only & Card \& Cash & Cash \& AW & Card only & Card \& $A W$ \\
\hline S_Senior_high & $-0.408 * * *$ & -0.192 & $-0.182 * * *$ & 0.151 & $0.207 *$ \\
\hline S_Vocational_college & $-0.405^{* * *}$ & $-0.388^{*}$ & -0.094 & $0.396^{*}$ & $0.397 * * *$ \\
\hline S_Junior_college & $-0.660 * * *$ & -0.065 & $-0.322 * * *$ & $0.485 * *$ & $0.400 * * *$ \\
\hline S_University & $-0.384 * * *$ & -0.109 & $-0.269 * * *$ & $0.573 * *$ & $0.375^{* * *} *$ \\
\hline S_Graduate & 0.094 & $1.197 * * *$ & 0.498 & $0.785 * *$ & $0.645^{* *}$ \\
\hline Full_time & -0.126 & 0.182 & -0.058 & 0.065 & -0.08 \\
\hline Part_time & 0.104 & $0.325^{*}$ & 0.099 & 0.168 & -0.025 \\
\hline Self_employed & $0.234 * *$ & 0.022 & $0.235^{* * *}$ & -0.21 & $-0.236^{* *}$ \\
\hline Student & $0.766^{* * *}$ & -0.814 & -0.079 & $1.009 * * *$ & $-1.014 * *$ \\
\hline S_Full_time & 0.078 & -0.162 & 0.01 & $-0.373^{* * *}$ & $-0.350 * * *$ \\
\hline S_Part_time & -0.023 & -0.082 & 0.02 & -0.036 & -0.072 \\
\hline S_Self_employed & $0.247 * *$ & $0.392 * *$ & 0.081 & 0.022 & $-0.264 * *$ \\
\hline S_Student & -0.234 & $-13.074 * * *$ & 0.181 & -0.58 & 0.451 \\
\hline No_spouse & 0.026 & -0.233 & 0.076 & 0.032 & -0.152 \\
\hline Top20cities & $0.286^{* * * *}$ & $0.336^{* *}$ & $-0.128 * *$ & $0.838 * * *$ & $0.385^{* * *}$ \\
\hline Cities_40k_ & 0.037 & 0.111 & $-0.098 * *$ & $0.427 * * *$ & $0.202 * * *$ \\
\hline Cities_20k_40k & 0.066 & -0.026 & -0.018 & 0.179 & 0.027 \\
\hline Year2007 & 0.077 & $-1.051 * * *$ & 0.097 & $-1.395 * * *$ & $-0.752 * * *$ \\
\hline Year2008 & 0.021 & $-0.951 * * *$ & 0.091 & $-1.181 * * *$ & $-0.758 * * *$ \\
\hline Year2009 & 0.007 & $-0.607 * * *$ & $0.152 * *$ & $-0.946^{* * *}$ & $-0.427 * * *$ \\
\hline Year2010 & 0.037 & $-0.340 * * *$ & $0.109 *$ & $-0.574 * * *$ & $-0.283 * * *$ \\
\hline Year2011 & -0.007 & $-0.250 *$ & $0.145 * *$ & $-0.393 * * *$ & -0.043 \\
\hline Year2012 & -0.04 & $-0.303 * *$ & $0.173 * * *$ & $-0.297 * * *$ & $-0.161 * *$ \\
\hline Year2013 & -0.082 & $-0.254 * *$ & 0.042 & -0.127 & 0.009 \\
\hline Mattress_NA & $0.436 * *$ & -0.023 & -0.133 & 0.478 & -0.541 \\
\hline income_NA & $-0.331 * * *$ & -0.059 & $-0.357 * * *$ & 0.25 & 0.156 \\
\hline asset_NA & -0.103 & 0.257 & 0.068 & -0.012 & 0.099 \\
\hline Dep_Ins_NA & -0.373 & -0.323 & 0.139 & -0.308 & 0.523 \\
\hline Banking_NA & 0.213 & -0.477 & 0.137 & 0.486 & -0.474 \\
\hline Debt_NA & -0.038 & -0.757 & -0.085 & -0.864 & -0.435 \\
\hline Homeowner_NA & -0.237 & -0.456 & $-0.618 * * *$ & -0.213 & -0.188 \\
\hline$a g e \_N A$ & 0.102 & $-0.880 * *$ & 0.239 & $-1.220 * *$ & $-1.202 * * *$ \\
\hline Male_NA & 0.505 & 0.664 & 0.053 & 0.422 & -0.305 \\
\hline job_NA & -0.108 & 0.096 & 0.073 & $0.379 *$ & -0.256 \\
\hline$S \_j o b \_N A$ & 0.181 & -0.309 & -0.009 & -0.168 & -0.089 \\
\hline Education_NA & 0.131 & 0.386 & $-0.189^{*}$ & 0.285 & 0.151 \\
\hline S_Education_NA & $-0.315^{* *}$ & 0.036 & -0.056 & 0.374 & 0.067 \\
\hline Constant & $-0.387 *$ & $-1.448 * * *$ & $-0.467 * * *$ & $-2.090 * * *$ & $-1.218 * * *$ \\
\hline Number of observations & 29,031 & & & & \\
\hline PseudoRsq & 0.097 & & & & \\
\hline LLR & -36936.07 & & & & \\
\hline
\end{tabular}

${ }^{*} p<0.10, * * p<0.05, * * * p<0.01$ 
Table 12 Results for multinomial logit estimation (4): single-person households

\begin{tabular}{|c|c|c|c|c|c|}
\hline Base: AW only & Cash only & Card \& Cash & Cash \& AW & Card only & Card \& AW \\
\hline Mattress & $0.778 * * *$ & 0.253 & $0.615^{* * *}$ & -0.15 & -0.061 \\
\hline income_O & 0.136 & $-0.298^{*}$ & -0.175 & 0.029 & -0.134 \\
\hline Income_100_180 & 0.086 & 0.066 & -0.015 & $0.285^{* *}$ & 0.153 \\
\hline Income_180_250 & 0.034 & 0.109 & 0.093 & $0.294 * * *$ & $0.399 * * *$ \\
\hline Income_250_300 & -0.174 & 0.01 & -0.063 & $0.384 * * *$ & $0.331 * * *$ \\
\hline Income_300_350 & 0.036 & 0.155 & -0.074 & $0.466^{* * * *}$ & $0.328 * * *$ \\
\hline Income_350_400 & 0.148 & 0.241 & -0.049 & $0.414^{* * *}$ & $0.377 * * *$ \\
\hline Income_400_500 & 0.209 & $0.369 * *$ & 0.002 & $0.702 * * *$ & $0.530 * * *$ \\
\hline Income_500_ & $0.380 * * *$ & 0.237 & -0.109 & $0.763 * * *$ & $0.342 * * *$ \\
\hline asset_0 & $0.185^{*}$ & -0.139 & $0.210 * *$ & -0.117 & $-0.212 * *$ \\
\hline asset_30_70 & $-0.278 * *$ & -0.111 & -0.217 & -0.025 & -0.013 \\
\hline asset_70_120 & $-0.392 * * *$ & 0.152 & -0.074 & $0.234 *$ & $0.205^{*}$ \\
\hline asset_120_21 & $-0.617 * * *$ & 0.229 & -0.182 & $0.230 *$ & $0.228 *$ \\
\hline asset_214_35 & $-0.652 * * *$ & 0.154 & $-0.388 * *$ & 0.139 & 0.19 \\
\hline asset_350_550 & $-1.095 * * *$ & -0.051 & $-0.360 * *$ & $0.299 * *$ & $0.276^{* *}$ \\
\hline asset_550_880 & $-1.259 * * *$ & 0.026 & $-0.344 * *$ & $0.372 * * *$ & $0.513 * * *$ \\
\hline asset_880_1550 & $-1.217 * * *$ & 0.107 & $-0.427 * *$ & $0.330 * *$ & $0.600 * * *$ \\
\hline asset_1500_2 & $-1.215^{* * *}$ & 0.062 & $-0.589 * * *$ & $0.317 * *$ & $0.756^{* * *}$ \\
\hline asset_2800_ & $-1.583 * * *$ & 0.243 & $-0.702 * * *$ & $0.451 * * *$ & $0.836^{* * * *}$ \\
\hline Know Deposit Insurance & $-0.607 * * *$ & $-0.199 * * *$ & $-0.188 * * *$ & -0.017 & $0.407 * * *$ \\
\hline Heard of Deposit Insurance & $-0.523 * * *$ & $-0.312 * * *$ & $-0.223 * * *$ & $-0.181 * * *$ & $0.128 * *$ \\
\hline Lower service charges & $-0.326^{* * *}$ & -0.092 & $0.154 * *$ & 0.056 & $0.269 * * *$ \\
\hline Online banking & $-0.202 * * *$ & $0.215^{* * * *}$ & $0.162 * * *$ & $0.406^{* * *}$ & $0.518^{* * *}$ \\
\hline Debt & -0.056 & $0.327 * * *$ & $0.320 * * *$ & 0.075 & $0.358 * * *$ \\
\hline Homeowner & $-0.601 * * *$ & $-0.292 * * *$ & $-0.455^{* * *}$ & 0.086 & -0.018 \\
\hline age $25-29$ & 0.157 & $0.456^{* * *}$ & 0.002 & $0.485^{* * *}$ & $0.173 *$ \\
\hline age $30-34$ & 0.053 & $0.345^{* * *}$ & 0.078 & $0.412 * * *$ & 0.121 \\
\hline age 35-39 & 0.068 & 0.039 & 0.005 & $0.234 * *$ & -0.078 \\
\hline age $40-44$ & -0.082 & -0.108 & 0.148 & -0.039 & -0.116 \\
\hline age 45-49 & -0.131 & $-0.445 * * *$ & -0.164 & $-0.290 * *$ & $-0.356^{* * * *}$ \\
\hline age $50-54$ & $-0.220^{*}$ & $-0.794 * * *$ & $-0.252 *$ & $-0.309 * *$ & $-0.464 * * *$ \\
\hline age 55-59 & $-0.477 * * *$ & $-0.847 * * *$ & -0.171 & $-0.584 * * *$ & $-0.503 * * *$ \\
\hline age 60-64 & $-0.375^{* * *}$ & $-1.284 * * *$ & -0.143 & $-0.842 * * *$ & $-0.893^{* * *}$ \\
\hline age 65-69 & $-0.426^{* *}$ & $-1.831 * * *$ & $-0.357 * *$ & $-1.068 * * *$ & $-0.978 * * *$ \\
\hline Male & $0.620 * * *$ & $0.145^{* *}$ & $0.161^{* * *}$ & -0.013 & $-0.269 * * *$ \\
\hline Vocational college & $-0.419 * * *$ & -0.175 & $-0.568 * * *$ & 0.004 & 0.052 \\
\hline Junior college & $-0.326^{* *}$ & 0.09 & $-0.443 * * *$ & $0.490 * * *$ & 0.103 \\
\hline University & $-0.476^{* * *}$ & -0.023 & $-0.455^{* * *}$ & 0.247 & 0.127 \\
\hline Graduate & $-0.715^{* * *}$ & -0.001 & $-0.551 * * *$ & $0.447 * *$ & $0.484 * * *$ \\
\hline Fulltime & -0.078 & -0.07 & $-0.237 * *$ & 0.113 & -0.048 \\
\hline Parttime & $0.206^{*}$ & 0.024 & 0.123 & 0.048 & 0.019 \\
\hline Selfemployed & $0.200^{*}$ & -0.05 & $0.195 *$ & $-0.234 * *$ & -0.081 \\
\hline
\end{tabular}


Table 12 (continued)

\begin{tabular}{llllll}
\hline Base: AW only & Cash only & Card \& Cash & Cash \& AW & Card only & Card \& AW \\
\hline Student & -0.205 & $-0.574^{* * *}$ & $-0.251^{*}$ & $-0.607^{* * *}$ & $-0.496^{* * *}$ \\
Seniorhigh & $-0.317^{* *}$ & -0.179 & $-0.386^{* * *}$ & 0.129 & 0.06 \\
Tohoku & -0.204 & -0.068 & $-0.441^{* * *}$ & -0.11 & 0.09 \\
Kanto & 0.015 & 0.063 & $-0.297^{* * *}$ & 0.109 & 0.064 \\
Hokuriku & -0.244 & $-0.378^{*}$ & -0.205 & $-0.315^{*}$ & $-0.300^{*}$ \\
Chubu & $-0.331^{* *}$ & 0.018 & $-0.427^{* * *}$ & 0.047 & -0.027 \\
Kinki & 0.024 & 0.194 & $-0.411^{* * *}$ & 0.126 & -0.018 \\
Chugoku & -0.16 & -0.19 & -0.127 & -0.041 & 0.034 \\
Shikoku & $-0.425^{* *}$ & -0.252 & -0.204 & -0.175 & -0.161 \\
Kyushu & $-0.318^{* *}$ & -0.231 & $-0.409^{* * *}$ & $-0.446^{* * *}$ & $-0.231^{* *}$ \\
Year2007 & $-0.740^{* * *}$ & $-0.814^{* * *}$ & -0.138 & $-1.285^{* * *}$ & $-0.598^{* * *}$ \\
Year2008 & $-0.639^{* * *}$ & $-0.713^{* * *}$ & -0.091 & $-1.062^{* * *}$ & $-0.635^{* * *}$ \\
Year2009 & $-0.587^{* * *}$ & $-0.602^{* * *}$ & -0.007 & $-0.792^{* * *}$ & $-0.496^{* * *}$ \\
Year2010 & $-0.630^{* * *}$ & $-0.344^{* * *}$ & -0.054 & $-0.643^{* * *}$ & $-0.263^{* * *}$ \\
Year2011 & $-0.736^{* * *}$ & $-0.363^{* * *}$ & -0.167 & $-0.527^{* * *}$ & $-0.360^{* * *}$ \\
Year2012 & $-0.486^{* * *}$ & $-0.227^{*}$ & -0.026 & $-0.435^{* * *}$ & $-0.212^{* *}$ \\
Year2013 & $-0.308^{* * *}$ & 0.037 & -0.117 & $-0.168^{*}$ & $-0.199^{* *}$ \\
Constant & $0.652^{* * *}$ & -0.442 & 0.245 & $-0.587^{* *}$ & $-0.402^{*}$ \\
Number of observations & 19,249 & & & & \\
PseudoRsq & 0.082 & & & & \\
LLR & -30166.02 & & & & \\
\hline
\end{tabular}

${ }^{*} p<0.10,{ }^{* *} p<0.05,{ }^{* * *} p<0.01$

\section{References}

Bagnall, J., Bounie, D., Huynh, K. P., Kosse, A., Schmidt, T., \& Schuh, S. (2016). Consumer cash usage: A cross-country comparison with payment diary survey data. International Journal of Central Banking, 12(4), 1-61.

Chen, H., Felt, M., \& Huynh, K. P. (2017). Retail payment innovations and cash usage: Accounting for attrition by using refreshment samples. Journal of the Royal Statistical Society, A180(2), 503-530.

Dubin, J. A. (1982). Economic theory and estimation of the demand for consumer durable goods and their utilization: Appliance choice and the demand for electricity. Ph.D. Dissertation. Massachusetts Institute of Technology. https://dspace.mit.edu/bitstream/handle/1721.1/102707/09915639-MIT. pdf? sequence $=1 \&$ isAllowed $=y$. Accessed 17 June 2020 .

Dubin, J. A., \& McFadden, D. L. (1984). An econometric analysis of residential electric appliance holdings and consumption. Econometrica, 52(2), 345-362.

Esselink, H., \& Hernández, L. (2017). The use of cash by households in the euro area. European Central Bank, Occasional Paper Series, No. 201.

Foster, K., Meijer, E., Schuh, S., \& Zabek, M. A. (2009). The 2008 survey of consumer payment choice. Federal Reserve Bank of Boston, Public Policy Discussion Papers, 2009, No. 9-10.

Foster, K., Greene, C., \& Stavins, J. (2019). The 2018 survey of consumer payment choice: Summary results. Federal Reserve Bank of Atlanta, Research Data Reports, 2019, No. 19-02.

Fujiki, H. (2019). How do we choose to pay using evolving retail payment technologies? Some additional results from Japan. Tokyo Center for Economic Research, TCER Working Paper Series, No. E-135.

Fujiki, H. (2020). Cash demand and financial literacy: A case study using Japanese survey data. Japan and the World Economy, 54, 1-20. 
Fujiki, H., \& Nakashima, K. (2019). Cash usage trends in Japan: Evidence using aggregate and household survey data. Paper presented at the Deutsche Bundesbank Fourth International Cash Conference, 10-12 September 2019, Munich, Germany.

Fujiki, H., \& Tanaka, M. (2018a). How do we choose to pay using evolving retail payment technologies? Evidence from Japan. Journal of The Japanese and International Economies, 49(C), 85-99.

Fujiki, H., \& Tanaka, M. (2018b). Choice of payment instruments for low-value transactions in Japan. In Deutsche Bundesbank (Ed.), War on cash: Is there a future for cash? International cash conference 2017 (pp. 416-468). Frankfurt am Main: Deutsche Bundesbank.

Greene, C., O’Brien, S., \& Schuh, S. (2017). U.S. consumer cash use, 2012 and 2015: An introduction to the Diary of Consumer Payment Choice. Federal Reserve Bank of Boston, Research Data Reports Paper, No. 17-6.

Haasl, T., Schulhofer-Wohl, S., \& Paulson, A. (2018). Understanding the demand for currency at home and abroad. Federal Reserve Bank of Chicago, Chicago Fed Letter, No. 396.

Henry, C. S., Huynh, K. P., \& Welte, A. (2018). 2017 Method-of-payments survey results. Bank of Canada, Bank of Canada Staff Discussion Paper, No. 2018-17.

Japanese Bankers Association. (2019). Yoriyoi ginkouzukuri no tameno ankeito no kekka ni tsuite. (The results of a survey for a better banking service.), (in Japanese). https://www.zenginkyo.or.jp/filea dmin/res/news/news310207_1.pdf. Accessed 17 June 2020.

Jonker, N., Hernández, L., de Vree, R., \& Zwaan, P. (2018). From cash to cards: How debit card payments overtook cash in the Netherlands. De Nederlandsche Bank, DNB Occasional Studies, No. 1601.

Kahn, C., \& Roberds, W. (2009). Why pay? An introduction to payments economics. Journal of Financial Intermediation, 18(1), 1-23.

Khiaonarong, T., \& Humphrey, D. (2019). Cash use across countries and the demand for central bank digital currency. International Monetary Fund, IMF Working Paper, No. 19/46.

Koulayev, S., Rysman, M., Schuh, S., \& Stavins, J. (2016). Explaining adoption and use of payment instruments by U.S. consumers. The RAND Journal of Economics, 47(2), 293-325.

Lacker, J. M. (2005). Payment economics and the role of central banks. Speech at the Bank of England Payments Conference, London, England, May 20, 2005.

Li, B. G., McAndrews, J., \& Zhu, W. (2019). Two-sided market, R\&D and payments system evolution. Federal Reserve Bank of Richmond, Working Paper, No.19-3.

Lippi, F., \& Secchi, A. (2009). Technological change and the households' demand for currency. Journal of Monetary Economics, 56(2), 222-230.

Lusardi, A., \& Mitchell, O. S. (2014). The economic importance of financial literacy: Theory and evidence. Journal of Economic Literature, 52(1), 5-44.

Mochizuki, A. (2019). Kessai koudokani kansuru torikumizyoukyouni tsuite. (Recent developments of advanced settlement technology.), (in Japanese), Paper presented to the Advanced Settlement Technology Promotion Public-Private Council, Financial Services Agency of Japan, January 29, 2019. https://www.fsa.go.jp/singi/kessai_kanmin/siryou/20190129/03.pdf. Accessed 15 Mar 2019

Nemoto, T. (2008). Ginko ATM no rekishi. (History of ATMs in banks.), (in Japanese), Tokyo: Nihon Keizai Hyouronsha.

Nosal, E., \& Rocheteau, G. (2011). Money, payments, and liquidity. Cambridge: MIT Press.

Otani, A., \& Suzuki, T. (2008). Background to the high level of banknotes in circulation and demand deposits. Bank of Japan, Bank of Japan Review, No. 2008-E-5. https://www.boj.or.jp/en/research/ wps_rev/rev_2008/data/rev08e05.pdf. Accessed 15 Mar 2019.

Rysman, M., \& Schuh, S. (2017). New innovations in payments. Innovation Policy and the Economy, 17, 27-48.

Rysman, M., \& Wright, J. (2014). The economics of payment cards. Review of Network Economics, 13(3), 303-353.

Schuh, S., \& Briglevics, T. (2014). US consumer demand for cash in the era of low interest rates and electronic payments. European Central Bank, European Central Bank Working Paper Series, No. 1660.

Stavins, J. (2002). Effect of consumer characteristics on the use of payment instruments. Federal Reserve Bank of Boston, New England Economic Review, Q3, 19-31.

Stavins, J. (2017). How do consumers make their payment choices? Federal Reserve Bank of Boston, Research Data Reports Paper, No. 17-1.

The Committee on Payments and Market Infrastructures. (2016). A glossary of terms used in payments and settlement systems. https://www.bis.org/dcms/glossary/glossary.pdf?scope=CPMI\&base=term. Accessed 17 June 2020. 
Wakamori, N., \& Welte, A. (2017). Why do shoppers use cash? Evidence from a shopping diary. Journal of Money, Credit and Banking, 49(1), 115-169.

Publisher's Note Springer Nature remains neutral with regard to jurisdictional claims in published maps and institutional affiliations. 